\title{
Validating presupposed versus focused text information
}

\author{
Murray Singer $^{1,2} \cdot$ Kevin G. Solar ${ }^{1} \cdot$ Jackie Spear $^{1}$
}

Published online: 2 December 2016

(C) Psychonomic Society, Inc. 2016

\begin{abstract}
There is extensive evidence that readers continually validate discourse accuracy and congruence, but that they may also overlook conspicuous text contradictions. Validation may be thwarted when the inaccurate ideas are embedded sentence presuppositions. In four experiments, we examined readers' validation of presupposed ("given") versus new text information. Throughout, a critical concept, such as a truck versus a bus, was introduced early in a narrative. Later, a character stated or thought something about the truck, which therefore matched or mismatched its antecedent. Furthermore, truck was presented as either given or new information. Mismatch target reading times uniformly exceeded the matching ones by similar magnitudes for given and new concepts. We obtained this outcome using different grammatical constructions and with different antecedent-target distances. In Experiment 4, we examined only given critical ideas, but varied both their matching and the main verb's factivity (e.g., factive know vs. nonfactive think). The Match $\times$ Factivity interaction closely resembled that previously observed for new target information (Singer, 2006). Thus, readers can successfully validate given target information. Although contemporary theories tend to emphasize either deficient or successful validation, both types of theory can accommodate the discourse and reader variables that may regulate validation.
\end{abstract}

Murray Singer

murray.singer@umanitoba.ca

1 University of Manitoba, Winnipeg, Manitoba, Canada

2 Department of Psychology, University of Manitoba, Winnipeg, Canada R3T 2N2
Keywords Language comprehension · Reading $\cdot$ Situation models $\cdot$ Text processing $\cdot$ Memory

Language understanding depends on the analysis of word meaning, grammatical structure, and sentence semantics. Full comprehension, furthermore, requires the integration of sentence meaning with prior discourse information and world knowledge. Successful integration enables the construction of an evolving situation model of the message. Consensus is emerging that another fundamental aspect of language comprehension is the continual scrutiny of message consistency by processes of verification, or "validation," with evidence of close resemblance between validation in reading and listening (van Berkum, Hagoort, \& Brown, 1999; van Berkum, Zwisterlood, Hagoort, \& Brown, 2003). In the present study, we investigated reading validation.

Readers' sensitivity to discourse congruence is evident at multiple levels of representation. Reading-time inflation, a central index of incongruence detection, has been documented for inconsistencies both at relatively shallow levels (i.e., surface and text base; Klin, 1995; Long \& Chong, 2001) and regarding the causal, spatial, and temporal situations underlying discourse (Albrecht \& Myers, 1995; O’Brien \& Albrecht, 1992; Rinck, Hähnel, \& Becker, 2001). Furthermore, converging evidence suggests that validation is immediate (van Berkum et al., 1999) and nonstrategic (Isberner \& Richter, 2013), and that it functions as a criterion for representational updating (e.g., Rapp \& Kendeou, 2009; Schroeder, Richter, \& Hoever, 2008).

However, these generalizations are qualified by a variety of validation constraints. Of those, the present study scrutinized people's well-known tendency to overlook discrepancies between presupposed sentence information and its referents. For example, the question, How many 
animals of each kind did Moses take on the ark?, which fallaciously presupposes the role of Moses, frequently evokes the answer "two" (Erickson \& Mattson, 1981). Such outcomes appear at odds with claims about effective reading validation.

For that reason, we conducted four experiments to determine whether readers are sensitive to discrepancies that are embedded in text presuppositions. In the introduction, we describe our theoretical framework, examine validation failures with an emphasis on discrepant presuppositions, and outline the experimental approach and corresponding hypotheses.

\section{Theoretical framework}

According to the validation analysis of Singer (2006), comprehension is appreciably regulated by memorybased text processes, text validation processes resemble those of intentional verification, and validation sometimes fails. We subscribed to those tenets and consider them here. First, the memory-based text-processing framework (e.g., McKoon \& Ratcliff, 1998; O’Brien, Lorch, \& Myers, 1998) holds that each successive text constituent presents tacit cues for ideas held over in working memory, and for the passive retrieval of (a) relevant world knowledge and (b) antecedent text ideas that may have been purged from working memory by interference or decay. Ideas that are so retrieved are said to resonate to the current constituent. They are restored to working memory, which enables their comparison with the contents of the current text segment. The basic principles of memorybased text processing were initially explored with reference to relatively simple text units (e.g., the striped animal; O'Brien \& Albrecht, 1992). Singer (2006) emphasized, however, that validation is pursued with reference to individual words, phrases, and clauses. That is, both simple concepts and complex propositions comprise tacit memory cues and are subjected to validation.

According to the second tenet, parsimony offers the hypothesis that the processes of text validation will resemble those of intentional sentence verification. That is, fully understanding a discourse sentence such as The pupil said that two is not odd depends in part on those processes that enable the verification of the true-false statement Two is not odd. In one experiment relevant to this point, Singer (2006, Exp. 1b) varied the truth and polarity (affirmative, negative) of target sentences. Target reading times mimicked the sentence verification finding that, whereas the verification time is greater for false than for true affirmatives, the opposite is observed for negatives (Clark \& Chase, 1972). That reading-time profile was embedded in a complex interaction with other text variables (Singer, 2006). Finally, a third tenet states that engaging in validation does not ensure its success. This point will be amplified with respect to certain validation failures, considered next.

\section{A validation failure: overlooking presupposed text inconsistencies}

Generalizations about discourse validation are qualified by contrasting shortcomings of comprehension monitoring. Texts that bear complex, detailed information may impede validation (Glenberg, Sanocki, Epstein, \& Morris, 1987; Otero \& Kintsch, 1992). Advanced age may play a role in failures to detect conspicuous text contradictions, such as a woman making sandwiches in the absence of bread (Cohen, 1979). Readers low in the predisposition to access relevant text and world knowledge exhibit validation profiles different from "high-access" readers (Singer \& Doering, 2014). A full treatment of discourse validation must address such systematic failures.

One conspicuous impediment to validation is illustrated by a riddle ending in where to bury the survivors (Barton \& Sanford, 1993) and trick questions like How many animals of each kind did Moses take on the ark? (none-it was Noah; Erickson \& Mattson, 1981). These examples share the property of embedding crucial terms in sentence presuppositions. The trick question presupposes that Moses collected animals, and focuses on the number of animals.

The latter results raise the question of whether presupposed discourse information might receive curtailed validation processing. In fact, an appreciable literature has been concerned with the processing of discourse presuppositions. In the remainder of this section, we briefly consider (a) the distinction between presupposed and focused information, (b) evidence of diminished scrutiny of presuppositions, and (c) some subtleties in the processing of presupposed versus focused ideas.

Given and new discourse ideas The concept of presupposition derives from the linguistic distinction between information that is presupposed, or "given," in a sentence, versus focused or "new" information (Halliday, 1967; Haviland \& Clark, 1974). In the framework of Haviland and Clark's given-new strategy, "given" ideas are assumed by the communicator to be already familiar to the understander. "Focused" ideas, in contrast, are novel assertions about the presupposition. As such, the presupposition may be characterized as the sentence topic (Hockett, 1958). Accordingly, given information signals that its antecedent should be accessible in the evolving discourse situation model (Haviland \& Clark, 1974). The retrieval of the antecedent permits its integration with the new information, and consequently the updating of the discourse model. 
Given versus new discourse ideas may be distinguished by the contrastive use of indefinite and definite articles (e.g., $A$ lawyer $<$ new $>$ hated the doctor $<$ given $>$ ), and in spoken language, by intonational stress (e.g., The lawyer' $<$ new $>$ hated the doctor < given>; Lyons, 1977). Cleft and pseudo-cleft syntactic constructions also highlight the given-new distinction: For example, in the cleft sentence It was the crowd that enjoyed the music, it is apparent that crowd constitutes a new idea (Hornby, 1974). Apart from such specialized constructions, given ideas generally appear in sentence-initial positions (Lyons, 1977).

Superficial processing of given ideas There is evidence, stemming from several behavioral paradigms, that given discourse ideas are scrutinized less carefully than new ideas. On each trial of one study (Hornby, 1974), the subjects heard a sentence, then viewed a related picture for just $50 \mathrm{~ms}$, and finally reported whether the sentence matched the picture. The sentences clearly distinguished between a given and a new concept: For example, in What the girl is holding is the cat, girl is given and cat is new. The subjects overlooked $39 \%$ of discrepancies that resided in the new concept (a picture of a girl holding a dog), but fully $72 \%$ of the given discrepancies (a picture of a boy holding a cat).

In several famous studies, Loftus demonstrated that fallacious question information is more likely to be incorporated in event representations if it is given than if it is new. In one study (Loftus \& Zanni, 1975), after viewing a film clip depicting no broken headlight prior to a car accident, subjects subsequently were asked either Did you see the broken headlight? (headlight given) or Did you see a broken headlight? (headlight new). The subjects later made more incorrect reports of the appearance of headlight in the given than in the new condition. Likewise, people are inclined to report that a film showed a nonexistent barn after being asked a question in which barn is given, such as How fast was the white sports car going when it passed THE BARN while traveling along the country road? (Loftus, 1975).

Deficient scrutiny of given sentence elements raises the possibility that subsequent memory might be worse for given than for new concepts. To address this question, Singer (1976) presented subjects with stimuli that distinguished given from new, such as the "cleft" sentence It was the king who led the troops. By various measures and in a variety of syntactic constructions, his subjects exhibited worse memory for the given concept, troops, than for the new concept, king.

These findings all meshed with subsequent Moses illusion findings (Erickson \& Mattson, 1981; Reder \& Kusbit, 1991) and related results (Barton \& Sanford, 1993). As we discussed earlier, a central feature of How many animals of each kind did Moses take on the ark? is that it presupposes Moses and focuses on the number of animals. In fact, a direct evaluation of the role of presupposition in the Moses illusion was performed by Bredart and Modolo (1988). They found that the illusion error occurred more often with the usual form of the question than when Moses was focal rather than presupposed, as in the declarative, It was Moses who took two animals of each kind on the ark.

Subtleties of processing given sentence information These cumulative findings promoted further refinements in characterizing the processing of given sentence information. Reder and Kusbit (1991) considered the possibility that given sentence elements are inadequately encoded. In one experiment presenting numerous Moses illusion questions, their subjects were instructed to answer the How many animals . . . ? question with "two" if it mentioned Noah, but with "can't say" if it mentioned Moses. They nevertheless detected a considerable incidence of Moses illusion replies. Critically, the reading times for the Moses version of How many animals . . . ? were about equal when the subjects did and did not commit the illusion error. Reder and Kusbit concluded that the illusion does not result from a failure to encode the presupposition about Moses.

Conrad and Rips (1986) noted that deficiencies in processing given information might suggest that new sentence information is processed before given information. However, in a complex design, they detected that, across a number of syntactic constructions, picture-sentence verification times were uniformly fastest when discrepancies between the sentence and the picture appeared in the given sentence element. This indicated that given was processed before new information: That is, the subject's detection of a discrepancy between the given information and the picture permitted the immediate registration of a "false" response, resulting in fast verification. The processing of given before new sentence information is consistent with the given-new strategy tenet that given information provides access to relevant discourse antecedents.

Conclusion Evidence converging from subjects' judgments and memory about sentences and from their question answering indicates that less scrutiny is applied to given than to new sentence information. This suggested to us that validation might be curtailed or even absent for presupposed or given sentence information. This study was designed to investigate that issue empirically. Our approach will be outlined shortly, as described in the Design and Predictions section.

We emphasize that this study scrutinized validation with reference to antecedent facts within rather than between messages. In addition, the critical relations among target and antecedent facts were based on strong, uncontroversial relations (e.g., both trucks and buses are vehicles), rather than false, new, or obscure facts and relations (e.g., Most forms of mental illness are contagious; Gerrig \& Prentice, 1991). 


\section{Design and predictions}

In new experiments, we used Singer's (2006) procedure to compare the validation of presupposed, given sentence information versus focal, new information. In this method, an early narrative sentence presents one of two concepts, as in Closer inspection revealed that the spill was coffee/Coke. In a subsequent target sentence, a character thinks or says something about one of the concepts, as in Leaning on the counter, her boyfriend realized that the spill was coffee. Depending on whether the target sentence concept matches its antecedent, the character's claim is accurate or inaccurate. The central measure in these experiments is target-sentence reading time. The paradigm has revealed that numerous discourse variables, including truth, polarity (affirmative, negative), and verb class interactively modulate validation (Singer, 2006, 2009). These effects have been very stable and have been diagnosed by event-related potentials (ERPs; Ferretti, Singer, \& Patterson, 2008) as well as by reading times.

Previously in this project, in a passage concerning a truck or a bus, the critical target-sentence concept had appeared in the new constituent of the sentence, as in The policeman comprehended that the vehicle with the flat was a truck. Here, that structure was compared, for the first time, with one in which the central concept was given, as in The policeman comprehended that the truck that Dan passed had a flat.

Three result patterns seemed possible. First, the failure to validate given concepts, suggested by previous findings of impoverished processing of presuppositions, would yield a Match $\times$ Focus interaction. Specifically, target reading times would be greater in the mismatch than in the match condition with new sentence elements, but not with given ones. This profile would likely also yield a match main effect. Second, if validation of given information were diminished but not absent, significant match effects would be detected in both the given and the new conditions, but the former effect would be smaller. This outcome would also be marked by a Match $\times$ Focus interaction.

Third, and in contrast, the thorough validation of given as well as of new sentence information would yield a reading-time match main effect and no Match $\times$ Focus interaction. We subscribed to this alternative for theoretical and empirical reasons. Psycholinguistic theory emphasizes that given information accesses the concepts in longterm memory with which new sentence information is to be integrated (Halliday, 1967; Haviland \& Clark, 1974). Memory-based theory posits that the current text information, whether given or new, comprises cues for the passive retrieval of antecedent information (O'Brien et al., 1998). Both of these devices afford the detection of discrepancies between given information and its antecedents. From an empirical perspective, our previous findings of thorough validation of new sentence content (Ferretti et al., 2008;
Singer, 2006, 2009) certainly raised the possibility that given information might likewise be validated.

These alternatives were tested in four experiments. Experiment 1 comprised the initial evaluation of the main hypotheses. In Experiment 2, we asked whether the main result pattern would generalize to a different grammatical construction. Experiment 3 was designed to demonstrate that these validation processes, for both given and new text concepts, proceed successfully with increased distance between the target concept and its antecedent.

The thrust of Experiment 4 was somewhat different. A central feature of the present analysis is that matching interacts informatively with other text variables that impact validation (Singer, 2006), including polarity (affirmative, negative) and the factivity of the main verb (e.g., factive know vs. nonfactive think). Singer (2006) had documented a clear Match $\times$ Factivity interaction for new target concepts, and in Experiment 4 we assessed whether a comparable profile would be obtained for given information.

We note that only the condition in which matching was manipulated in the new sentence component (the new condition of Exp. 1) constituted a direct replication of Singer (2006). All other given and new conditions of Experiments 1-4 present novel findings.

\section{Experiment 1}

To recapitulate, in the first experiment we measured reading times for targets that matched or mismatched their antecedents. In this project, we had previously examined only target sentences in which the central concept was new, such as truck in The policeman comprehended that the vehicle with the flat was a truck. Here that structure was compared, for the first time, with one in which the central concept was given, as in The policeman comprehended that the truck that Dan passed had a flat. Notwithstanding the impoverished processing of sentence presuppositions that has been revealed by certain paradigms (e.g., Erickson \& Mattson, 1981; Hornby, 1974), we predicted that readers would validate both given and new information. In our design, this would result in a match main effect and no Match $\times$ Focus interaction. We advanced this prediction because of the crucial role that given information serves in linking the current text with its antecedent (Haviland \& Clark, 1974; O’Brien, Shank, Myers, \& Rayner, 1988).

\section{Method}

Subjects The subjects were 74 native English-speaking male and female students of introductory psychology at the University of Manitoba. They participated in partial fulfillment of a course requirement. All four experiments in this study were conducted in compliance with the ethical 
standards of the American Psychological Association for interacting with human subjects.

Materials The materials were based on 14 experimental, 26 filler, and four practice passages that Singer (2006, Exp. 2) derived from the passages of O'Brien, Plewes, and Albrecht (1990, Exp. 1). Fourteen of the 26 filler passages were sixsentence narratives. The remaining 12 filler passages and the four practice passages were four-sentence narratives. Most importantly, the experimental passages were seven sentences long; one appears in Table 1. Sentence 2 identified two candidate concepts for a particular event, such as coffee versus Coke, and Sentence 3 selected one of those candidates. The target, Sentence 6, always mentioned one of the two alternatives; in this case, coffee. Thus, the content of Sentence 6 either matched or mismatched Sentence 3.

Sentence 6 also manipulated the new versus given status of the crucial concept. For this example, the critical concept, coffee, was presented as either new information (before the slash in Table 1) or given information (after the slash). In all previous studies in this project (e.g., Ferretti et al., 2008; Singer, 2006, 2009), the critical concept had appeared as new information in the target sentence. Thus, four versions of the passage represented the crossing of Match $\times$ Focus (new, given).

The given critical concepts were usually modified by the definite article the and appeared in the initial position of the complement clause (Lyons, 1977), as in The policeman comprehended that THE TRUCK that Dan passed had a flat. However, these devices were sometimes used singly. In other instances, cleft constructions distinguished given versus new (e.g., The coach was certain that it was oranges $<$ new $>$ that Ken ate $<$ given $>$ ). Some variation among given-new devices was dictated by the precise form of the experimental passages and was intended to minimize given-new incongruence (Yekovich, Walker, \& Blackman, 1979).

It is noteworthy that Sentence 2 mentioned both of the candidate critical concepts. Thus, regardless of the match condition, the critical concept in Sentence 6 had been previously mentioned in the passage. Finally, a true-false comprehension test statement was composed for each passage, half with the correct answer "yes." Among the 14 experimental passages, five of the statements addressed the critical concept, and nine did not. The passage in Table 1 happens to have a test statement about the critical concept, Coke versus coffee.

Appendix A shows the 28 experimental passages that were used in the four experiments of this study, only 14 of which were manipulated in Experiment 1. ${ }^{1}$ The four experiments

\footnotetext{
${ }^{1}$ Only 14 experimental passages were used in Experiment 1 because, apart from the added comparison of given versus new critical concepts, the experiment constituted a precise replication of the half of Singer's (2006) Experiment $1 \mathrm{~b}$ that scrutinized factive verbs. There were 14 experimental passages in that half-experiment.
}

Table 1 Sample materials of Experiments 1, 2, and 4

Passage

Martha and Sue were trying to stay up all night to study for final exams. (Sentence 1)

A sticky sensation made Martha realize that she had spilled some coffee or Coke on the counter. (Sentence 2)

Closer inspection revealed it was coffee/Coke. (Antecedent: Sentence 3)

Both Martha and Sue had their first exam at 8 A.M. the following morning. (Sentence 4)

Martha's boyfriend had gotten an A on the first exam so Martha and Sue were anxious to study with him. (Sentence 5)

Leaning on the counter, he [thought (nonfactive, Exp. 4 only) /realized (factive)] that (New: the spill was coffee/Given: the coffee there was sticky). (Target: Sentence 6)

No-mmonia was the product for this job. (Sentence 7)

Test statement

The spill on the counter was Coke. (correct answer depended on the match condition)

cumulatively allowed us to inspect numerous conditions. The notes at the top of Appendix A explain how the passages were composed for each experiment.

From these materials, four experimental lists were constructed. For List 1, either three or four of the experimental passages were randomly assigned to the four conditions obtained by crossing match and focus. The experimental and filler passages were assigned to random list positions, subject to the following restrictions. Each half of the list (disregarding the practice passages) included seven six-sentence fillers, six four-sentence fillers, and at least one of experimental passages in each condition. No two consecutive experimental passages could represent the same condition.

Lists $2-4$ were constructed by cycling the experimental passages across the Match $\times$ Focus conditions, following a Latin-square procedure. As a result, each list had either three or four experimental passages in each condition, and each experimental passage occurred once in each condition across the four lists.

Procedure The sessions were conducted in separate, closed rooms at stations comprising a personal computer, monitor, and keyboard. The monitor was positioned $22 \mathrm{~cm}$ from the near edge of its table, but the subject could otherwise adjust the chair for comfort. In each session, up to four subjects were randomly assigned to view a different one of the four lists.

The subject initiated each trial by pressing the keyboard space bar, labeled "Ready." The first sentence of the passage appeared at row 10, column 1, of a 20-row screen. The subject was instructed to read the sentence for comprehension and to press "Ready" again to view the next sentence. The instructions did not mention the presence of text inconsistencies, nor did those of the other experiments. Each sentence immediately 
replaced the previous one at the same screen location. If the subject did not respond to a sentence within $10 \mathrm{~s}$, the next sentence automatically replaced it.

The last sentence of each passage was followed by a 2.5 -s interval. Then, a fixation "X" appeared for $500 \mathrm{~ms}$ at row 10 , column 1 , followed by the comprehension statement. The " $x$ " and "." keys were used to respond "false" and "true," respectively. There was no response time limit. The subject's response was followed by a 3-s interval, after which the screen signal "READY" initiated the next trial.

After the four practice passages and the first 20 experimental and/or filler passages, a 30 -s rest period occurred. Then, the message READY blinked for $10 \mathrm{~s}$, after which the subject could initiate the next trial. At the end of the session, a screen message thanked the subject.

\section{Results}

The data of three subjects who committed six or more out of 14 possible errors on the experimental-passage comprehension statements were discarded, consistent with the exclusion criterion of Singer (2006). The data of another subject, who seldom signaled comprehension of the target sentence within the 10-s limit, were likewise excluded. All analyses are based on the data of the remaining 70 subjects.

The mean accuracy on the experimental-passage comprehension statements was $79.3 \%$. The data of greatest interest were the reading times of the experimental-passage target sentences (Sentence 6). These values appear as a function of match and focus in Table 2 . The reading times were subjected to analysis of variance (ANOVA), alternately treating subjects $\left(F_{1}\right)$ and items $\left(F_{2}\right)$ as the random effect. With subjects random, match and focus were the within- variables, and list was a between- variable. Likewise, with items random, match and focus were the within- variables, and verbal set was a between- variable. Verbal set refers to the group of experimental passages that appeared in the same condition in a given list. List and verbal set served counterbalancing purposes and held no theoretical interest. Therefore, their effects are not reported.

The ANOVA revealed a match main effect, $F_{1}(1,66)=22.33$, $M S E=503,141, \eta_{p}^{2}=.25 ; F_{2}(1,10)=12.67, M S E=193,831, \eta_{p}^{2}$ $=.56$. The reading time was greater when the target sentence mismatched than when it matched the antecedent Sentence 3. The reading time was significantly greater for critical-given than for critical-new targets by subjects, $F_{1}(1,66)=6.92, M S E=$ $386,398, \eta_{p}^{2}=.10$, but not by items, $F_{2}<1$. The Match $\times$ Focus interaction did not approach significance, $F_{\mathrm{S}} \leq 1{ }^{2}$

\footnotetext{
${ }^{2}$ Although reading times have not previously been trimmed in this project (e.g., Singer, 2006), all subjects-random ANOVAs in this study were repeated with trimming criteria included. Specifically, reading times that were lower than 1,500 $\mathrm{ms}$ and higher than two standard deviations above the condition mean for each subject were excluded. These analyses yielded exactly the same effects as those reported in Experiments 1-4.
}

Table 2 Mean target reading times (in milliseconds; $S E$ in parentheses) as a function of match and focus in Experiments 1,2, and 3

\begin{tabular}{llllll}
\hline Experiment & Match & \multicolumn{2}{l}{ Focus } & & \\
\cline { 3 - 6 } & & New & & Given & \\
\hline Experiment 1 & Match & 3,557 & $(252)$ & 3,662 & $(225)$ \\
& Mismatch & 3,910 & $(198)$ & 4,156 & $(226)$ \\
Experiment 2 & Match & 3,069 & $(134)$ & 3,306 & $(103)$ \\
& Mismatch & 3,376 & $(143)$ & 3,728 & $(146)$ \\
Experiment 3 & Match & 3,287 & $(149)$ & 3,505 & $(124)$ \\
& Mismatch & 3,494 & $(113)$ & 3,738 & $(125)$ \\
\hline
\end{tabular}

One concern was that recurring patterns of inconsistency in the experimental passages might have induced the subjects to adopt strategies that enhanced the detection of text mismatches. Consistent with this possibility, the match effect was slightly larger in the second half $(503 \mathrm{~ms})$ than in the first half $(402 \mathrm{~ms})$ of the list. However, in an items-random ANOVA in which list half served as an additional betweenitems variable, the Match $\times$ List Half interaction did not approach significance, $F_{2} \approx 1$. This issue will receive further attention in Experiment 2.

\section{Discussion}

The rationale of Experiment 1 was that evidence has indicated that readers do not scrutinize the accuracy of given sentence information as carefully as new information. That raised the possibility that the usual target-antecedent match or consistency effect would be observed for new but not for given concepts. However, Experiment 1 refuted that proposal: There was a robust match main effect, and the Match $\times$ Focus interaction did not approach significance. The latter effect constitutes a null outcome, but the match effect was of greater magnitude in the given than in the new condition. This is opposite to the pattern that would be expected if there were any curtailment of validation of given sentence information. Thus, the results are consistent with our main prediction and refute the alternatives of absent or curtailed validation of given sentence information. They attest to the generality and robustness of text validation processes.

We observed a trend toward greater target reading times when the critical information was given rather than new. This was likely due to a slight difference between target length in those conditions. The number of characters in critical-given target sentences exceeded that of critical-new targets by $4.1 \%$, and reading times were $4.7 \%$ greater for critical-given than for critical-new targets.

The experimental passages were not constructed so as to evaluate the relative contributions of definiteness versus clause-initial position to concept givenness. However, the fact 
that doctor is clearly given in the sentence $A$ lawyer hated the doctor indicates that definiteness strongly signals that a concept constitutes given information.

Throughout this project, and in Experiment 1 here, the target sentence used the main-verb-plus-complement structure illustrated in Sentence 6 of Table 1. Experiment 2 was designed to determine whether the results profile of Experiment 1 would generalize to target sentences with a different grammatical construction.

\section{Experiment 2}

Given information ideally appears in sentence subjects, which facilitates the retrieval of discourse antecedents (Yekovich et al., 1979). The complement structure of Experiment 1 may have modified the retrieval function of the given concept. For example, it might be argued that the entire complement of the main verb is focused rather than presupposed. Therefore, in Experiment 2 the qualifying phrase that identified the narrative character's thoughts (Table 1 , Sentence 6) was moved to the end of the target sentence. As a result, the noun representing the critical concept appeared in the main clause of the target sentence. Sentences $1 \mathrm{a}$ and $1 \mathrm{~b}$, with the critical concept coffee, exemplify the new and given target sentences of Experiment 2, respectively.

(1) a. The spill on the counter was coffee, her boyfriend realized. (coffee new)

b. The coffee on the counter was sticky, her boyfriend realized. (coffee given)

\section{Method}

Subjects The subjects were 77 new individuals sampled from the same population as in Experiment 1.

Materials In Experiment 2, all 28 of the passages of Appendix A were manipulated and so constituted experimental items. In each of these passages, the leading verb phrases of the target sentences were rewritten to become modifying phrases at the end of the sentences. This is illustrated in Example 1 above. In four counterbalanced lists, the experimental passages were cycled across the four Match $\times$ Focus conditions.

In List 1 , seven passages were randomly assigned to each condition, subject to the restriction that at least three of the passages in each condition appear in each half of the list. No two consecutive experimental passages represented the same condition. Six four-sentence filler passages appeared in random positions in each half of the list. For the other three lists, a
Latin-square procedure was used to cycle the passages across conditions. As a result, each list had seven passages in each condition, and across the four lists, each experimental passage appeared once in each condition. In all other respects, the list construction was the same as in Experiment 1.

We modified in two ways the 14 passages that were converted from fillers in Experiment 1 to experimental in Experiment 2. First, the qualifying phrase was moved to the end of the target sentence. Second, a new Sentence 2 was added to the passage. It mentioned the two alternatives, such as coffee and Coke (see Table 1).

We considered that the subjects of these experiments might detect the repetitive form of the experimental passages, in spite of the presence of the practice and filler materials. We created a questionnaire to address this issue, comprising five main questions plus subquestions. The questionnaire items proceeded from open-ended and vague to more leading and specific. The questionnaire appears in Appendix B.

Procedure The experimental-task procedure was identical to that of Experiment 1. After completing that task, the subjects wrote their answers to the questionnaire items.

\section{Results}

The data of two subjects who provided reading times under the 10-s limit for few of the target sentences were discarded. All analyses focused on the data of the remaining 75 subjects.

Reading times The mean accuracy rate for the comprehension statements was $82.3 \%$. The mean target reading times appear in Table 2. ANOVA was applied to these values, using the same scheme as before. Reading times were greater in the mismatch than in the match condition, $F_{1}(1,71)=32.13$, MSE $=402,444, \eta=.31 ; F_{2}(1,24)=20.89, M S E=178,068, \eta_{p}^{2}=$ .46. The focus main effect was significant, with reading times being greater in the given than in the new condition, $F_{1}(1,71)$ $=39.68, M S E=128,538, \eta_{p}^{2}=.36 ; F_{2}(1,24)=8.39, M S E=$ 291,154, $\eta_{p}^{2}=.26$.

As in Experiment 1, the Match $\times$ Focus interaction was not significant by items, $F_{2}<1$, but it was significant by subjects, $F_{1}(1,71)=4.78, M S E=140,726, \eta_{p}^{2}=.06$. However, the match effect was numerically greater in the given than in the new focus condition, a pattern opposite to the one that would support curtailed validation of the given target information. Nevertheless, we evaluated the match effect using tests of simple main effects. The match effect was significant in the new condition, $F_{1}(1,71)=15.05, M S E=256,011, \eta_{p}^{2}=.18$; $F_{2}(1,24)=9.38, M S E=140,783, \eta_{p}^{2}=.28$. Likewise, it was significant in the given condition, $F_{1}(1,71)=33.96, M S E=$ $287,158, \eta_{p}^{2}=.32 ; F_{2}(1,24)=16.85, M S E=147,900, \eta_{p}^{2}=.41$.

As in Experiment 1, we performed an items-random ANOVA in which list-half was an additional between-items 
variable. The Match $\times$ List-Half interaction again did not approach significance, $F_{2}<1$. In addition, the match effect was numerically smaller for the second than for the first half of the list. This outcome is inconsistent with the possibility that noticeable regularities among the experimental passages promoted the gradual development of validation strategies.

Questionnaire The questionnaire was scored for all but the two disregarded subjects. In it we presented both twoalternative items and open-ended items. The results of the former appear in Table 3. Question 2 was of minor interest. For Item 3, 47\% of subjects reported detecting "something special" about the passages. With further guidance, $60 \%$ of all subjects indicated that they had detected a repeating pattern in the passages (Item 4). In addition, 37\% of all subjects reported adopting a special strategy for performing the experiment (Item 5).

The subjects frequently elaborated on positive answers to Items 3-5. Cumulatively across those items, $16 \%$ of subjects commented on the presentation of two alternatives in the passage (e.g., coffee and Coke in Table 1). The resolution of which of those alternatives was veridical (e.g., in Sentence 3 of Table 1 , it was coffee) was noted by $15 \%$ of the subjects. Finally, $36 \%$ of subjects were aware that the target sentence later either confirmed or denied the former resolution. These values are not strictly mutually exclusive among subjectsrather, some subjects were, for example, aware both of the two alternatives and the later confirmation or denial.

Of the $37 \%$ of all subjects (Table 3 ) who described strategies for performing the task, about two thirds $(26 \%$ of all subjects) presented sundry and often ambiguous or irrelevant ones. However, a deliberate intention to retain both of the two alternatives of Sentence 2 was reported by $4 \%$ of all subjects. A nonoverlapping $8 \%$ of subjects not only focused on those alternatives but subscribed to the resolution that was asserted first-namely, in Sentence 3. The sum of $12 \%$ for the latter two groups is small, but it likely somewhat underestimates the prevalence of relevant strategies, in view of subjects' disinclination to provide detailed questionnaire replies.

Table 3 Percentages of affirmative answers to the two-alternative items of the Experiment 2 questionnaire

\begin{tabular}{lll}
\hline Item number and content & \multicolumn{2}{l}{ Answer } \\
\cline { 2 - 3 } & Yes & $\begin{array}{l}\text { No, or no } \\
\text { answer }\end{array}$ \\
\hline 2. Comprehension questions easy? & 95 & 05 \\
3. Anything special about passages? & 47 & 53 \\
4. Repeating pattern in passages? & 60 & 40 \\
$\begin{array}{l}\text { 5. Did that pattern or anything else prompt you } \\
\text { to adopt a special strategy? }\end{array}$ & 37 & 63 \\
\hline
\end{tabular}

Target reading times as a function of strategy (relevant vs. [irrelevant + none]) appear in Table 4 . Both groups exhibited match effects of at least $298 \mathrm{~ms}$ in both the new and given conditions. The mean reading times were appreciably greater for the strategic than for the nonstrategic readers, with means of 3,979 ms $(S E=208)$ and 3,274 ms $(S E=100)$, respectively. Full ANOVA was not applied to these values, in view of the small $n$ of the relevant-strategy group. However, it was determined that even in the nonstrategy group, reading times were significantly greater in the mismatch than in the match condition for given targets, $F_{1}(1,57)=31.52, M S E=169,001, \eta_{p}^{2}=$ .36 .

\section{Discussion}

Theoretical psycholinguistic treatments of processing given versus new sentence information have mainly inspected relatively simple grammatical constructions (Halliday, 1967; Haviland \& Clark, 1974; Hornby, 1972). In contrast, in Experiment 1 we scrutinized target sentences using a mainverb-plus-complement form. This was intended to maximize the comparability between the present experiments and prior findings in this project. To enhance the salience of the given versus new status of the present critical concepts, we phrased the target sentences of Experiment 2 as simple actives followed by a qualifying verb phrase (e.g., the boyfriend realized). The reading times of Experiment 2 mimicked the profile of Experiment 1, providing reassurance that the robust matching effects for both new and given critical concepts was not a function of an idiosyncratic grammatical construction. The Experiment 2 outcome was based on twice as many experimental passages as had been inspected in Experiment 1.

As in Experiment 1, the focus main effect likely resulted from a difference in the mean lengths of the given versus the new targets: Critical-given target sentences had 7.3\% more characters than did critical-new targets, and reading times were $9.2 \%$ greater for critical-given than for critical-new targets.

Table 4 Mean target reading times (in milliseconds; $S E$ in parentheses) as a function of match, focus, and strategy in Experiment 2

\begin{tabular}{llllll}
\hline Strategy & Match & \multicolumn{2}{l}{ Focus } & & \\
\cline { 3 - 6 } & & New & & Given & \\
\hline \multirow{2}{*}{ Relevant } & Match & 3,644 & $(208)$ & 3,668 & $(225)$ \\
& Mismatch & 4,037 & $(243)$ & 4,567 & $(261)$ \\
& Difference & 393 & & 899 & \\
Irrelevant or none & Match & 2,989 & $(100)$ & 3,065 & $(108)$ \\
& Mismatch & 3,299 & $(117)$ & 3,363 & $(125)$ \\
& Difference & 310 & & 298 & \\
\hline
\end{tabular}


Questionnaire The questionnaire was administered to determine whether the subjects' detection of recurring patterns in the passages prompted them to focus on the comparison of the antecedent and the critical target information, whether given or new. Sixty percent of the subjects expressed awareness of the competing pair of alternatives in the experimental passages, although in most cases a prompt was required for them to do so (Items 3 and 4).

Notwithstanding awareness of some of the regularities of the experimental passages, only $18 \%$ of all subjects described strategies that would have enhanced their attention to the critical concepts. Three features of the data discourage the notion that the overall match effect for given target information was due to the development of strategies. First, even the nonstrategic subjects had greater mismatching than matching reading times in the given condition. Second, if the recurring patterns in the passages promoted strategies that enhanced detecting text mismatches, then the impact of such strategies should increase with the total number of experimental passages. To the contrary, however, Experiment 2 had double the number of passages, but a smaller mean matching effect $(364 \mathrm{~ms})$ than in Experiment 1 (423 ms). Third, and likewise, the match effect was not greater in the second than in the first half of the list.

The possibility of subjects devising special reading strategies does not inherently contradict a default passive validation mechanism. Certainly, reading with special goals and strategies such as learning, memorizing, and summarizing (e.g., Cirilo, 1981; Mayer \& Cook, 1981) may alter the quality of reading processes. For example, reading narratives with the goal of detecting spelling errors disrupts robust processes of inference computation (Singer \& Halldorson, 1996). Likewise, approaching a narrative with a personal goal, such as learning about women's rights in the Middle Ages, will affect default comprehension processes so as to yield qualitatively unique representations (Kintsch, 1980). More generally, conspicuous instances of incoherence or disfluency may demand that the reader deploy remedies that are controlled and/ or strategic (Gernsbacher, 1990; Winkielman, Huber, Kavanagh, \& Schwarz, 2012). We consider these reactions to be comprehension-enhancing remedies rather than alternatives to passive validation mechanisms.

We note that the numerically greater mean target reading times for strategy than for nonstrategy subjects is consistent with a more deliberate approach to the task in the former individuals. To summarize, experimental studies of language processing require the presentation of appreciable numbers of stimuli of a common form. This always raises the possibility that subjects will strategically capitalize on that regular form. The questionnaire in Experiment 2 confirms that the subjects could identify some of the commonalities among the passages, but it tends to deny that they developed strategies that might have perturbed the main results.
Conclusion Experiments 1 and 2 yielded clear evidence that people detect mismatches in given as well as in new discourse concepts. In the next experiment, we turned our attention to the reconciling of discourse concepts and their antecedents across greater spans of intervening text.

\section{Experiment 3}

As we discussed earlier, we subscribe to the memory-based text-processing framework, according to which discourse concepts comprise implicit memory cues for their antecedents (e.g., McKoon \& Ratcliff, 1998; O’Brien et al., 1998). It is important to demonstrate that, within limits, validation proceeds successfully even when those antecedents no longer reside in working memory. In Experiments 1 and 2, two locally coherent sentences (Sentences 4 and 5, Table 1) intervened between the antecedent and the target. This is considered adequate to purge the antecedent propositions from working memory (Fletcher, 1981; Kintsch \& van Dijk, 1978; McKoon \& Ratcliff, 1992). Nevertheless, in Experiment 3, the text intervening between the antecedent and target was increased to four locally coherent sentences, comparable to the stimuli of some other studies (O'Brien et al., 1998; Singer \& Halldorson, 1996, Exp. 2b). Apart from that change, in Experiment 3 we again asked whether text validation proceeds effectively for both given and new sentence information.

\section{Method}

Subjects The subjects were 76 new individuals randomly sampled from the same population as before.

Materials The original passages of O'Brien et al. (1990) included six optional sentences that could intervene between what in the present experiments were the antecedent (viz. Sentence 3) and target sentences. For Experiment 3, the 28 experimental passages were modified to add two more intervening sentences between the antecedent and the target. These revisions generally used the verbatim or modified intervening sentences from O'Brien et al. (1990). The revised passages were locally coherent, and the intervening material did not refer to the distinct concepts of the antecedent sentence. Table 5 shows the Experiment 3 form of the coffee/Coke spill story. The extra intervening sentences of the other passages appear in Appendix A.

Two sentences were also added to the four practice passages and 12 filler passages so that they would more closely resemble the experimental passages. As a result, the practice and filler passages were six sentences long. As in Experiment 1, the target sentences used a main-verb-plus-complement 
Table 5 Sample materials of Experiment 3 (added sentences in ALL CAPS)

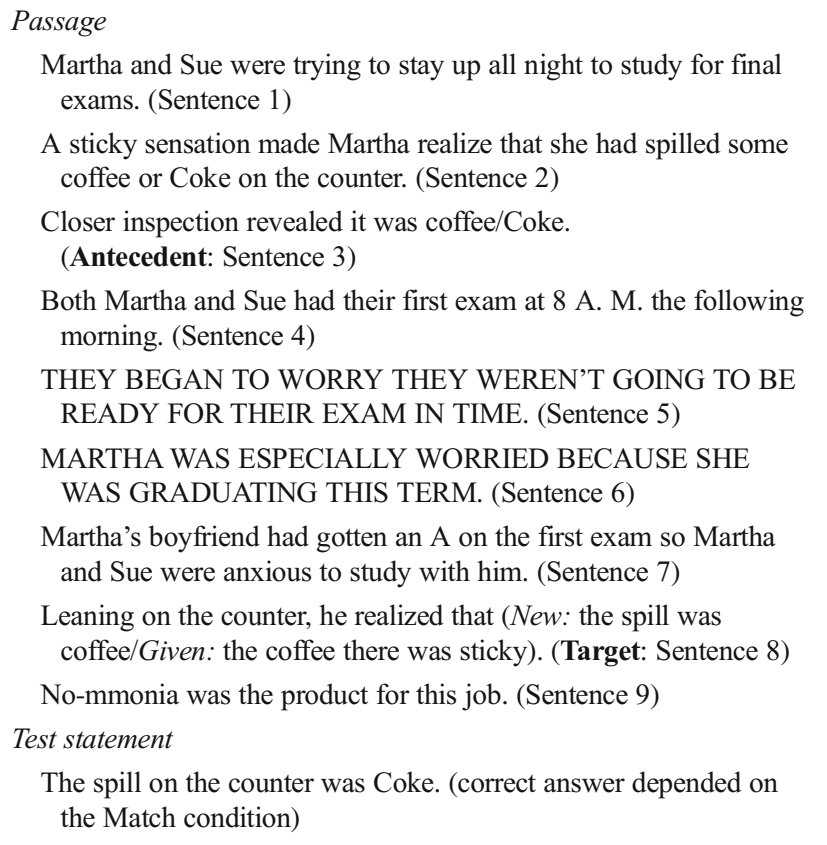

construction. Apart from that construction and the two extra intervening sentences, the materials of Experiment 3 were the same four lists that had been inspected in Experiment 2.

Procedure The procedure was identical to that of the previous experiments.

\section{Results and discussion}

Four subjects made errors on 12 or more of the comprehension statements that accompanied the experimental passages. This was proportionally the same cutoff criterion that we had applied in Experiment 1. All analyses were applied to the data of the remaining 72 subjects.

The mean accuracy on the comprehension statements was $78.4 \%$. The mean reading times as a function of matching and focus appear in Table 2. ANOVA revealed that mismatching exceeded matching reading times, $F_{1}(1$, $68)=13.92, M S E=204,512, \eta_{p}^{2}=.17 ; F_{2}(1,24)=17.80$, $M S E=76,328, \eta_{p}^{2}=.43$. Target reading times were greater in the given than in the new condition, $F_{1}(1,68)=21.38$, $M S E=143,469, \eta_{p}^{2}=.24 ; F_{2}(1,24)=4.18, M S E=$ $357,844, \eta_{p}^{2}=.15$, and the Match $\times$ Focus interaction was not significant, $F_{1}(1,68)=2.19, M S E=144,589$, $\eta_{p}^{2}=.03 ; F_{2}(1,24)=0.05, M S E=91,980, \eta_{p}^{2}=.00$.

The average match effect across Experiments 1 and 2, in which only two sentences intervened between the target sentence and its antecedent, was $394 \mathrm{~ms}$. The magnitude of the match effect in Experiment 3 was only $220 \mathrm{~ms}$.
This is consistent with a reduction of readers' ability to detect text mismatches with increasing target-antecedent distance (Albrecht \& Myers, 1995).

Finally, match effects of 301 and $158 \mathrm{~ms}$ were detected in the first and second halves of the list, respectively. However, an items-random ANOVA in which list-half was an additional between-items variable did not reveal the Match $\times$ List-Half interaction to be significant, $F_{2}(1,20)=1.92, M S E=$ $1,466,869, \eta_{p}^{2}=.09$. The magnitudes of the list-half match effects were inconsistent with the gradual development of intentional matching strategies.

To summarize, in Experiment 3, the number of locally coherent sentences that intervened between the antecedent and target sentences was increased to four. As in Experiments 1 and 2, reading times were appreciably greater in the mismatch than in the match condition, yielding a match main effect and no Match $\times$ Focus interaction. This provides reassurance that as a reader proceeds through a text, the content of the current text segment provides tacit retrieval cues for backgrounded antecedent material. Restoring the latter ideas to working memory enables the comparison between the current segment and corresponding antecedent ideas. As a result, the subjects readily detected mismatches, regardless of whether the mismatches appeared in the new or the given target information.

Finally, the main effect of focus was again attributed to slight sentence-length differences between the conditions. The critical-given targets had $7.3 \%$ more characters than the critical-new ones, and reading times were $6.8 \%$ greater for critical-given than for critical-new targets.

Consistency effects, whether for new or given text ideas, are compatible with a wide range of comprehension theories. However, a central aspect of our thesis is that these effects are regulated by interactions between matching and other factors. In this regard, matching interacts informatively with variables such as affirmative versus negative expression (Singer, 2006) and factive versus nonfactive main verb (Ferretti et al., 2008; Singer, 2006). To demonstrate that the quality of validation of given discourse concepts closely resembles that of new concepts, in Experiment 4 we scrutinized the Match $\times$ Factivity interaction in a design that presented only given target concepts. ${ }^{3}$

\footnotetext{
${ }^{3}$ Experiment 4 could alternatively have focused on the Match $\times$ AffirmativeNegative interaction. However, antecedent-target sequences such as Closer inspection revealed that the spill was Coke. ... Leaning on the counter, her boyfriend realized that the spill was NOT coffee. raise the pragmatic issue of "context of plausible denial" (Wason, 1965): That is, why would the status of coffee be relevant in this context? Singer's (2006) method addressed this hazard, but the Match $\times$ Factivity manipulation of Experiment 4 entirely avoided it.
} 


\section{Experiment 4}

The match between a target sentence and its antecedent interacts with the factivity of the main verb of the target sentence: Namely, a match versus mismatch effect is observed with factive but not with nonfactive verbs in both reading times and event-related potential (ERP) responses (Ferretti et al., 2008; Singer, 2006, Exp. 1b; Singer, 2009). Singer (2006) addressed that Match $\times$ Factivity interaction as follows. Factive verbs such as realized entail the truth of their complements, whereas nonfactive verbs such as thought do not. "Realizing" that coffee was spilled when, in fact, it was Coke, is blatantly incongruent. It has been proposed that, in addition to the usual impact of a mismatch (coffee vs. Coke) on reading time, coupling a factive verb with a false complement imposes a large pragmatic penalty on reading times. Conversely, Singer proposed that there is a pragmatic penalty when a nonfactive verb governs a matching complement, as in He thought that the spill was coffee. This reflects that the reader might wonder why the character only "thinks" this true fact, analogous to being puzzled upon reading Jill believed that the world was round (why does she only "believe" it?). The inflation of reading times due to pragmatic penalties in the factive mismatch condition and the nonfactive match conditions accounted for Singer's observed Match $\times$ Factivity interaction.

Evidence for the latter analysis stemmed from regression modeling of the validation reading times in an experiment that manipulated matching, polarity (affirmative, negative), and factivity (Singer, 2006, Exp. 1b). For this regression, we used three predictor variables. The first was constituent comparisons: that is, the number of elementary operations required to fully compare the target sentence with its antecedent (Carpenter \& Just, 1975). The second captured the aforementioned hypotheses about pragmatic reading time penalties. The third predictor was target-sentence syllable length. The model accounted for $99 \%$ of the variance among the eight Match $\times$ Polarity $\times$ Factivity reading time means. All three predictors were statistically significant and exhibited sensible regression coefficients.

In Experiment 4, we manipulated matching and verb factivity, using narratives in which the target sentences always treated a critical concept as part of the given information. We predicted a Match $\times$ Factivity interaction in target-sentence reading times that would resemble those detected in previous studies with new, rather than given, critical-sentence information. Such an outcome would indicate that comparable validation processes are applied to given and new discourse ideas.

\section{Method}

Subjects The subjects were 78 new individuals from the same population that had been sampled in the previous experiments.
Materials Appendix A shows that associated with the target sentence of each passage were alternative factive and nonfactive main verbs. These verbs were randomly chosen from lists of 33 factive and 30 nonfactive verbs, respectively. Most of these verbs were assigned to only one passage. With this arrangement, factivity constituted a within-items variable.

In four counterbalanced lists, the 28 experimental passages were cycled across four Match $\times$ Factive conditions. For the example in Table 1, the four versions were derived by crossing the alternatives in the antecedent-target sequence, Closer inspection revealed it was coffee/Coke. . . Leaning on the counter, he [thought (nonfactive)/realized (factive)] that the coffee there was sticky. In List 1, seven passages were randomly assigned to each condition, subject to the restriction that a minimum of three passages in each condition appeared in each half of the list. No two consecutive experimental passages represented the same condition. Six filler passages that were four sentences in length appeared in random positions in each half of the list, for a total of 12 fillers. For the other three lists, a Latin-square procedure was used to cycle the passages across conditions. As a result, each list had seven passages in each condition, and across the four lists, each experimental passage appeared once in each condition. In all other respects, the list construction was the same as in the prior experiments.

Procedure The procedure was identical to that of the previous experiments.

\section{Results and discussion}

One subject responded within the 10-s limit for very few of the experimental target sentences. All analyses are based on the data of the remaining 77 subjects. They responded correctly to a mean of $85.6 \%$ of the experimental-passage comprehension statements.

The mean target-sentence reading times are shown in Table 6. In both the subjects-random and items-random ANOVAs, both match and factivity were within- effects. In addition, list was a between-subjects variable in the subjectsrandom ANOVA, and verbal set was a between-items variable in the items-random ANOVA.

Table 6 Mean target reading times (in milliseconds; $S E$ s in parentheses) as a function of match and factivity in Experiment 4

\begin{tabular}{|c|c|c|c|c|}
\hline \multirow[t]{2}{*}{ Match } & \multicolumn{4}{|c|}{ Factivity } \\
\hline & Factive & & Nonfa & \\
\hline Match & 3,326 & (152) & 3,313 & (102) \\
\hline Mismatch & 3,654 & (118) & 3,331 & (103) \\
\hline
\end{tabular}


Most importantly, the Match $\times$ Factivity interaction was significant, $F_{1}(1,73)=4.70, M S E=131,829, \eta_{p}^{2}=.06 ; F_{2}(1$, 24) $=8.93, M S E=752,272, \eta_{p}^{2}=.27$. Tests of simple main effects revealed a match main effect in the factive condition, $F_{1}(1,73)=14.53, M S E=165,574, \eta_{p}^{2}=.17 ; F_{2}(1,24)=10.70$, $M S E=210,668, \eta_{p}^{2}=.31$, but not in the nonfactive condition, $F \mathrm{~s} \leq 1.07$. This pattern matches that of Singer (2006, Exp. 1b).

Both main effects were also significant. The reading times were greater in the mismatch than in the match condition, $F_{1}(1,73)=9.31, M S E=212,531, \eta_{p}^{2}=.11 ; F_{2}(1,24)=5.87$, $M S E=142,560, \eta_{p}^{2}=.20$. In addition, the reading time in the factive condition exceeded that in the nonfactive condition, $F_{1}(1,73)=9.68, M S E=182,702, \eta_{p}^{2}=.12 ; F_{2}(1,24)=$ $4.84, M S E=162,930, \eta_{p}^{2}=.17$. Both of those effects were subsumed in the Match $\times$ Factivity interaction.

To briefly review, Experiments 1-3 had yielded matching effects for critical concepts embedded in given as well as in new text information. That finding refuted the notion that readers might overlook discrepancies between given information and its antecedents, which would constitute a validation failure. Experiment 4 went further. There we proposed that the Match $\times$ Factivity interaction for given concepts would resemble the one previously measured for new concepts. Experiment 4 demonstrated precisely that: A consistency effect was observed in sentences with factive main verbs, but not with nonfactive verbs. The explanation, detailed at the outset of Experiment 4, is that pragmatic differences between factive and nonfactive sentences contribute to this outcome. We emphasize that validation processes are applied to nonfactive as well as to factive target sentences, but that the interaction between matching and factivity abolishes the nonfactive match effect.

However, Experiment 4 highlights the interesting subtlety that, by virtue of the main-verb-plus-complement structure of the target sentences, validation might be applied both to the knowledge of the reader and that of the narrative characters. Consider the target sentence (Martha's boyfriend) thought that the coffee there was sticky, in the context of a previous spill of Coke. Successful validation would result in the reader's detection of the coffee-Coke discrepancy. However, additional computations might be needed to represent the boyfriend's inaccurate state of belief. The latter processes might perturb reading times in some fashion.

This concern is diminished, but not completely eliminated, by the appearance in Experiment 2 of the qualifying phrase (Martha's boyfriend realized) at the end, rather than the beginning, of the target sentence. We note also that similarities between inference validation with respect to (a) narrative text (Singer, Halldorson, Lear, \& Andrusiak, 1992) and (b) expository text (Singer, Harkness, \& Stewart, 1997) suggest that the present effects would be similar without the complication of having to consider the character's state of knowledge. Future studies to corroborate this claim would have the merit of meshing with fine-grained theories of discourse representation such as Sanford and Garrod's (2005) scenario-mapping and focus theory.

\section{General discussion}

Successful comprehension entails the encoding of the discourse situation model. A coherent situation model, in turn, requires the constant monitoring of the consistency and accuracy of the message - processes that comprise validation (Cook \& O’Brien, 2014; Schroeder et al., 2008; Singer et al., 1992).

There has been noteworthy progress in documenting and characterizing discourse validation. The consistency effect provides a prevalent index of people's awareness of text incoherence. That is, reading times are inflated when descriptions are infelicitous regarding the locations (O'Brien \& Albrecht, 1992), time relations (Rinck et al., 2001), and character traits (Albrecht \& O’Brien, 1993; Rapp \& Kendeou, 2009) of text. Discourse incongruence also results in inflated ERP N400 responses and other neural measures (van Berkum et al., 1999). Consistency effects have promoted studies that have depicted validation as immediate and nonstrategic (Isberner \& Richter, 2013; van Berkum et al., 1999). Research has indicated that validation pertains to implicit as well as to explicit text content (Singer et al., 1992) and that it serves as a precondition for representational updating (Ferretti, Singer, \& Harwood, 2013; Schroeder et al., 2008).

Successful validation may be threatened by many discourse and reader factors. Of particular interest here were discourse constructions and devices that would mask indisputable inconsistencies, such as Where should the survivors be buried? (Barton \& Sanford, 1993) and How many animals of each kind did Moses take on the ark? (Erickson \& Mattson, 1981). One commonality among these examples is that the overlooked information (survivors, Moses) is embedded in a given sentence proposition (Haviland \& Clark, 1974). Research has shown that given sentence information is detected and remembered less well (Hornby, 1974, and Singer, 1976, respectively) than new information. This raised the question of whether validation would be less thorough for given than for new sentence ideas. We applied Singer's (2006) validation paradigm to this problem. ${ }^{4}$ In this method, the information in a narrative target sentence matches or mismatches an antecedent sentence. People are sensitive to discourse mismatches residing in the new component of

\footnotetext{
${ }^{4}$ The main method throughout these experiments was self-paced, fullsentence reading. Note, however, that Singer's (2006) methodology was devised as a reading-time analogue of Clark and Chase's (1972) sentence verification procedure, which evaluated the interactive impacts of truth and polarity (affirmative, negative) on verification times (see also Knoeferle, Urbach, \& Kutas, 2011).
} 
sentences, and matching interacts informatively with a variety of pragmatic features of discourse (Ferretti et al., 2008; Singer, $2006,2009)$. Four new experiments yielded reading-time mismatch effects that were highly similar for given and new target information. The effects were detected for target sentences bearing different grammatical constructions and appearing at different distances from their antecedents. In a design in which the critical information was always given (Exp. 4), the interactive signature between matching and verb factivity was highly similar to that observed for new critical information (Singer, 2006, Exp. 2).

Why, then, were given mismatches detected here, whereas they have been overlooked in well-known semantic-illusion studies? In the present study, the crucial stimuli were sentences that appeared in connected discourse. In connected discourse, presupposed or given sentence information signals that the understander should already know about the given entity. Most usually, that entity will have been previously mentioned in the text and successfully encoded. In other examples, such as Phil entered the restaurant. The waitress brought the menu, the antecedent for the presupposed waitress resides in world knowledge rather than in the discourse representation. In yet other circumstances, varying degrees and dimensions of incoherence will require the reader to initiate a new representational structure (Gernsbacher, 1990). Regardless, the search of memory for signaled antecedents of the current text promotes full comprehension. In instances of successful search, the resonating information and the given information will co-occur in working memory, providing the opportunity for validating comparison.

The critical stimuli in semantic-illusion studies have typically differed from ours in one or more ways. First, they have often invoked either world knowledge (Erickson \& Mattson, 1981; Reder \& Kusbit, 1991) or pictures or video (Hornby, 1974; Loftus, 1975), rather than the antecedent discourse. In the absence of an antecedent discourse representation, memory search may have been discouraged, precluded, or modified, resulting in a variety of indices of validation failure. Second, semantic-illusion test items have usually been questions rather than declarative sentences (Barton \& Sanford, 1993; Erickson \& Mattson, 1981; Hornby, 1974; Loftus, 1975; Reder \& Kusbit, 1991), and questions make an especially clear distinction between given and new information (Clark \& Haviland, 1977; Harris, 1973). This might prompt a reader to particularly scrutinize the new component, and therefore overlook given mismatches.

In yet other instances, subjects have read unrelated stimulus sentences and later received memory tests about them (Singer, 1976). In this regard, Singer observed that a sentence such as It was the king who led the troops ordinarily refers to a discourse representation that includes the given entity, troops. He noted that presenting this sentence without a context might be expected to enhance the processing of the given element, because the reader would not have had a prior opportunity to encode it. To the contrary, as we discussed in the introduction, Singer's subjects exhibited worse memory for the given concept, troops, than for the new concept, king. This outcome is consistent with the proposal that, without a discourse context, the usual memory search for the antecedents of given sentence information is curtailed. In that event, possible discrepancies between the given element and relevant world knowledge might be overlooked.

These proposals might be pursued empirically in a variety of ways. First, the pictorial stimuli of certain studies (Loftus, 1975) could be replaced with texts. Second, target sentences in coherent texts could use grammatical constructions that make especially strong distinctions between given and new information. These could include explicit questions, implicit questions (e.g., The policemen asked him what sort of vehicle had a flat; O'Brien et al., 1990), and cleft constructions. It is possible that, in contrast with the present results, given mismatches would be overlooked in target sentences using those constructions.

To further explore other grammatical constructions, future studies ought to more clearly distinguish the impacts of different devices signaling given versus new status. We noted in Experiment 1 that the target sentences in this study used sentence position, grammatical construction, and definiteness either singly or in combination to designate the given concepts. The precise form of the target sentences was guided by the coherence requirements of the naturalistic passages that we scrutinized. Disentangling the impacts of the different signals of sentence focus remains a task for future investigation.

\section{Readers' reactions to text inconsistencies}

The results raise the question of how readers reconcile text mismatches, whether given or new. There are many possible reactions to reading that Coke was spilled on the counter and then learning that a character establishes or claims that it was coffee. A reader could embrace either the earlier or the later conflicting concept, or else could retain both, perhaps in the expectation that a later resolution will be offered. According to the Experiment 2 questionnaire replies, many relevantstrategy subjects favored the first of the conflicting concepts. They wrote statements such as Always go with what they first said happened and Remember the initial statement and not concern myself with the statement presented after. Other individuals, in contrast, strived to maintain both options, stating Focused on the two choices what (sic) were given or Paid attention to the contradictory findings. Interestingly, no subjects expressed preferring the second alternative. This was in spite of the fact that the second option sometimes appeared in the complement of a factive verb, which might have suggested that it was veridical. 
These varied reactions to discourse inconsistencies mesh with a growing literature documenting the complex effects of contradictory text information. Consider some examples: Reading is slowed when a narrative character performs an action inconsistent with a trait of that character, even when that trait has been revised or even explicitly denied (Kendeou, Smith, \& O'Brien, 2013; O’Brien, Cook, \& Guéraud, 2010). Readers may consider cans of paint to be a possible cause of a fire even when the cans were absent on the day of the blaze (Wilkes \& Leatherbarrow, 1988). When a story describes a character's slovenly apartment, the reader's inference that he is messy is not negated by the simple disclaimer that this circumstance was atypical (Rapp \& Kendeou, 2009).

These findings imply that people's reactions to text incongruence are complex and heterogeneous, consistent with the present questionnaire replies. Also heterogeneous are the cognitive mechanisms that likely underlie the latter effects. Outdated information persists in influencing reading comprehension because, following a principle of memory-based text processing, it is not definitively eradicated from memory (O'Brien et al., 2010). The degree to which new, inconsistent information displaces its antecedent depends on its causal integration with the message. Thus, the knowledge that Albert is a sloppy person is displaced by the causal explanation that he had just moved, but not by the simple refutation that the messiness of his apartment was an exception (Rapp \& Kendeou, 2009; see also Kendeou et al., 2013). This occurs in part because text ideas of high causal interconnectivity are easily retrievable.

Routine validation in comprehension is immediate and routine, and it serves as a criterion for representational updating. However, the detection of discourse incongruence does not complete the comprehension process, but rather initiates diverse, complex remedies.

\section{Theoretical frameworks of validation successes and failures}

Validation failures Ultimately, it will be essential to address both validation successes and failures within comprehensive theories. Several theories highlight mechanisms that especially accommodate comprehension shortcomings. In this regard, the good-enough processing framework holds that the cognitive demands of comprehension often require processing to proceed on the basis of incomplete or erroneous representations (Ferreira, Bailey, \& Ferraro, 2002). Ferreira et al. proposed that such representations may result when the reader encounters complex or demanding constructions. Examples include garden path sentences such as While Anna dressed the baby played, and semantically misleading passives such as The dog was bitten by the man (the latter of which may result in the reader understanding the opposite).

One condition that regulates processing completeness is discourse focus (Sanford \& Garrod, 2005). Consider the following example:

(2) a. Everybody was wondering which man got into trouble.

b. Everybody was wondering what was going on that night.

(3) In fact, the man with the hat was arrested.

In the context of the antecedent Sentence $2 \mathrm{a}$, hat is considered to be in focus in Sentence 3 because it functionally distinguishes among individuals in the category "man." In contrast, hat is not in focus with reference to the antecedent Sentence $2 b$. According to the scenario-mapping and focus theory, the processing of nonfocal discourse concepts (e.g., hat while reading Sentences $2 \mathrm{~b}$ and 3) may be partial or incomplete (Sanford \& Garrod, 2005; Sanford \& Graesser, 2006). Focal status is a complex function of syntactic structure and discourse constraints. To the extent that presupposed concepts in isolated declarative and interrogative sentences do not have a discourse context, and therefore have ill-defined focal status, readers may overlook presupposed mismatches with reference to visual representations (e.g., Loftus, 1975) and relevant knowledge (e.g., Erickson \& Mattson, 1981).

Partial processing in the scenario-mapping and focus framework meshes with Reder and Kusbit's (1991) analysis of the Moses illusion. Their reading-time and answer-time data for Moses illusion sentences discounted the possibilities that the readers (a) "cooperatively" disregarded the anomaly and (b) failed to encode the crucial presupposition. Rather, Reder and Kusbit concluded that, having encoded the presupposition, their subjects performed only a partial match between the crucial concept and relevant world knowledge. The fact that people are not fooled by How many animals of each kind did Obama take on the ark? corroborates that at least a partial match is performed.

Validation successes In contrast, several theoretical analyses that have highlighted successful validation derive at least partly from Kintsch's $(1988,1998)$ construction-integration model $(\mathrm{CI})$. The CI model posits that readers initially construct a rich but imprecise network capturing the current text segment. Then, integration is realized as the settling of activation in that network, following principles of constraint satisfaction. These processes of integration favor the most highly interconnected parts of the network, effectively excluding tangential ideas. In 
contemporary refinements of this analysis, integration is considered to include mechanisms of validation and representational updating (Cook \& O'Brien, 2014; Ferretti et al., 2013; Richter \& Singer, in press; Schroeder et al., 2008). Cook and O'Brien characterized those processes as parallel and asynchronous.

Readers exhibit particularly striking sensitivity to discourse congruence at the interface of integration and validation. Consider that Jenny heard the mountain lion pacing in its cage is transiently anomalous at the word mountain because one cannot hear a mountain. In an eyetracking study, the processing time of that sentence was inflated within $300 \mathrm{~ms}$ of people's fixation of mountain (Staub, Rayner, Pollatsek, Hyönä, \& Majewski, 2007), relative to a nonanomalous version, Jenny SAW the mountain lion pacing in its cage. Thus, semantic monitoring meets the criterion of immediate processing and is not delayed until the wrap-up of the constituent. Furthermore, validation with reference to world knowledge is concurrent with rather than subsequent to semantic evaluation. Thus, the profiles of N400 ERP deflections are highly similar for Dutch trains are sour, which is semantically anomalous, and Dutch trains are white, which is inconsistent with the general knowledge that they are yellow (van Berkum et al., 1999).

Reconciliation between analyses that stress validation successes and those that highlight failures will arise from their consideration of the numerous factors that are likely to regulate validation. Among those factors are text complexity, readers' orienting task, reader characteristics, the distance between related text ideas, and the quality of the tacit retrieval cues of the current text segment (Singer, 2013). Indeed, most of these variables have already been scrutinized in the context of both theoretical positions. Science-text inferences that are successfully validated in relatively simple grammatical constructions (Singer et al., 1997) are thwarted in the context of more complex syntax (Noordman, Vonk, \& Kempff, 1992; see also Glenberg et al., 1987). There is evidence that language processes, including validation, are likely to be affected by readers' skill and working memory resources (Singer \& Doering, 2014; Swets, Desmet, Hambrick, \& Ferreira, 2007). Basic cognitive differences may underlie the validation deficits of older as compared to younger readers (Christianson, Williams, Zacks, \& Ferreira, 2006; Cohen, 1979). Finally, the detection of discourse incongruence is affected by the quality of the tacit retrieval cues in a text (Albrecht \& Myers, 1995).

In conclusion, previous findings had suggested that readers might systematically overlook discourse inconsistencies embedded in target-sentence presuppositions. However, four experiments based on an informative paradigm in this domain revealed that readers were as sensitive to presupposed mismatches as to focused ones. This effect was obtained across numerous conditions, involving different grammatical constructions and target-antecedent distances. The findings are consistent with extensive, accumulating evidence that readers continuously evaluate text congruence.

Author note This research was supported by Discovery Grant No. RGPIN/9800 from the Natural Sciences and Engineering Research Council of Canada. We are grateful to members of the Department of Psychology, University of South Carolina, who offered suggestions concerning this project. These data were presented at the meeting of the Psychonomic Society, in Minneapolis, November 2015.

\section{Appendix A Experimental materials of Experiments $1-4$}

The passages beginning with an asterisk $(*)$ are the 14 experimental passages of Experiment 1.

Key: The third sentence of each passage (the antecedent) presented one of two concepts (i/ii) that either matched (i) or mismatched (ii) the target sentence. The Complement/ Noncomplement $\times \mathrm{New} /$ Given sentences comprised four alternative versions of the target sentence. The noncomplement structure was used in Experiment 2, and the complement structure was used in the other experiments. The alternative verbs (i/ii) of the target sentences are factive and nonfactive, respectively. Only factive verbs were used in Experiments 1, 2, and 3, and verb factivity was manipulated in Experiment 4. The extra, intervening sentences in ALL CAPS appeared in Experiment 3 only.

*Dan had been driving all night in order to get home for Thanksgiving.

Before long, Dan drove past a truck or a bus which was stopped with a flat tire.

The rear-view mirror confirmed that it was a truck/bus.

He couldn't help but laugh because its spare tire must have been underneath everything and suitcases and boxes were strewn everywhere.

IT WASN'T LONG BEFORE THE SUN STARTED TO COME UP AND DAN FIGURED HE HAD ABOUT 100 MILES LEFT TO DRIVE.

HE HOPED HE'D BE HOME IN ONLY A COUPLE OF HOURS.

Later, while Dan was sitting in a diner, drinking some coffee, a policeman came in and started a conversation with him.

\section{TARGETS}

Complement/New: He comprehended/implied that the vehicle with the flat was a truck.

Complement/Given: He comprehended/implied that the truck that Dan passed had a flat.

Noncomplement/New: The vehicle with the flat was a truck, the cop comprehended.

Noncomplement/Given: The truck that Dan passed had a flat, the cop comprehended. 
Dan worried about what happened to the passengers of the vehicle.

Jim and a few of his friends decided to go hunting on the weekend.

On the way up the conversation centred on whether they would hunt deer or bear.

When they got to the warden's office, there were only deer/bear licences left.

They got to the cabin just before dark and they quickly unpacked the car.

THEY ATE AND WENT TO SLEEP RIGHT AWAY BECAUSE THEY WANTED TO GET UP BEFORE DAWN.

THE SLEEP DIDN'T SEEM TO HELP THEM VERY MUCH, HOWEVER.

They hiked through the woods all day and didn't see a thing. TARGETS

Complement/New: Jim's wife discovered/presumed that he had been hunting deer.

Complement/Given: Jim's wife discovered/presumed that the deer they were hunting were scarce.

Noncomplement/New: They had been hunting deer, Jim's wife discovered.

Noncomplement/Given: The deer they were hunting were scarce, Jim's wife discovered.

She had prepared a beautiful dinner.

Jerry had spent all day building a shed in his backyard when he noticed that the board for the windowsill wasn't straight.

Prying the board loose would require the wrench or the hammer.

Finally, he fixed it with the wrench/hammer.

The most difficult part of the project was putting the plumbing in the bathroom.

HE HOPED THAT HE REMEMBERED ENOUGH TO BE ABLE TO INSTALL IT CORRECTLY.

HOWEVER, HE TOOK COMFORT IN KNOWING THAT HIS UNCLE, A PLUMBER, WOULD BE GLAD TO HELP HIM.

When he was just about finished, his uncle came over to see how it was coming.

\section{TARGETS}

Complement/New: He verified/suspected that Jerry used a wrench to fix the windowsill.

Complement/Given: He verified/suspected that Jerry used the wrench to fix the windowsill.

Noncomplement/New: Jerry used a wrench to fix the windowsill, his uncle verified.

Noncomplement/Given: Jerry used the wrench to fix a windowsill, his uncle verified.

The job was competently done but far from professional.
*Ken enjoyed riding his bike to football practice in the afternoon with his brother.

It was very hot and Ken was glad his brother always brought along either some oranges or apples.

Today they gobbled oranges/apples as they rode along.

Since it was about a five mile ride from their house to the practice field, they figured they were getting a better workout than most of the other guys on the team.

SOMETIMES THEY WOULD RACE ALONGSIDE TRUCKS TO SEE HOW FAST THEY WERE GOING.

HOWEVER, TODAY, ABOUT HALF WAY TO PRACTICE, KEN DECIDED HE WOULD STOP TO TAKE A REST.

By the time they got to practice, Ken was feeling sick to his stomach.

\section{TARGETS}

Complement/New: The coach was certain/figured that it was oranges that Ken ate.

Complement/Given: The coach was certain/figured that Ken ate the oranges to beat the heat.

Noncomplement/New: It was oranges that Ken ate, the coach was certain.

Noncomplement/Given: Ken ate the oranges to beat the heat the coach was certain.

Everyone knew that they were sour at this time of year.

*Martha and Sue were trying to stay up all night to study for final exams.

A sticky sensation made Martha realize that she had spilled some coffee or Coke on the counter.

Closer inspection revealed it was coffee/Coke.

Both Martha and Sue had their first exam at $8 \mathrm{~A}$. M. the following morning.

THEY BEGAN TO WORRY THEY WEREN'T GOING TO BE READY FOR THEIR EXAM IN TIME.

MARTHA WAS ESPECIALLY WORRIED BECAUSE SHE WAS GRADUATING THIS TERM.

Martha's boyfriend had gotten an A on the first exam so Martha and Sue were anxious to study with him.

\section{TARGETS}

Complement/New: Leaning on the counter, he realized/ thought that the spill was coffee.

Complement/Given: Leaning on the counter, he realized/ thought that the coffee there was sticky.

Noncomplement/New: The spill was on the counter was coffee, her boyfriend realized.

Noncomplement/Given: The coffee on the counter was sticky, her boyfriend realized.

No-mmonia was the product for this job.

When Julie looked around her yard it was obvious to her that spring was not far away. 
Through the window, she was excited to spot a flock of either robins or crows.

A step outside showed that the birds feeding in her yard were robins/crows.

Julie began to think about how she was going to plant her garden.

THIS YEAR SHE WAS GOING TO PLANT VEGETABLES AS WELL AS FLOWERS.

SHE USUALLY DIDN'T PLANT ANYTHING UNTIL TOO LATE BUT THIS YEAR SHE WAS DETERMINED TO GET AN EARLY START.

Julie went to the garden to help her father who was already out there working.

\section{TARGETS}

Complement/New: He found out/claimed that the birds feeding in Julie's yard were robins.

Complement/Given: He found out/claimed that the robins in Julie's yard were eating the grass seed.

Noncomplement/New: The birds feeding in Julie's yard were robins, her father found out.

Noncomplement/Given: The robins in Julie's yard were eating the grass seed, her father found out.

Julie went inside for her birding guide.

When Max picked up his first customer of the evening in his cab, he sensed that there was something unusual about the man.

Max thought that he had noticed something strange about the man's tie or maybe it was his hat.

The rear-review mirror showed the man's blue tie/hat to be odd.

Max tried to start a conversation with the man but he didn't answer any of his questions so he gave up.

HE NOTICED THAT THE TRAFFIC WAS ESPECIALLY HEAVY HEADING INTO THE CITY SO HE DECIDED TO TAKE A SHORT CUT TO TRY AND BEAT IT.

FINALLY HE REACHED THE AIRPORT AND DROVE TO THE PROPER TERMINAL TO LET THE MAN OUT.

Later, while Max was cashing out, an F. B. I. agent wanted to talk to him about the man.

\section{TARGETS}

Complement/New: Max recollected/presumed that the man's odd garment was a hat.

Complement/Given: Max recollected/presumed that the man's hat was odd.

Noncomplement/New: The man's odd garment was a hat, Max recollected.

Noncomplement/Given: The man's hat was odd, Max recollected.

The agent wanted to know the man's destination.
*After a long afternoon of driving, Norm was shocked when he turned his street corner.

He recalled the long-range forecast for tornados or forest fires. His house had been destroyed in a tornado/fire.

Norm didn't know what to do so he got back in his car.

HE DECIDED TO STOP AT MCDONALDS AND GET A HAMBURGER.

ACTUALLY, HE HATED THE FOOD THERE BUT HE STOPPED ANYWAY BECAUSE HE KNEW IT WOULDN'T TAKE VERY LONG.

He drove to his cousin's to spend the night.

\section{TARGETS}

Complement/New: His cousin showed that/believed Norm's house was destroyed by a tornado.

Complement/Given: His cousin showed that/believed the tornado that destroyed Norm's house was rare.

Noncomplement/New: Norm's house was destroyed by a tornado, his cousin showed.

Noncomplement/Given: The tornado that destroyed Norm's house was rare, his cousin showed.

At that moment, all Norm really wanted was to go to sleep.

*For Harold's first trip for his new job, they were sending him into the desert to look at some land for possible future use.

He needed a pack animal for the trip so Harold talked to an old man who sold camels and mules.

Harold finally bought a camel/mule from the old man.

Harold took a couple of days to get together all of the supplies he thought he would need.

HE STARTED TO WORRY THAT HE WOULDN'T BE READY TO LEAVE ON TIME.

HE WANTED TO BE SURE HE WOULD BE PREPARED FOR ANY TYPE OF EMERGENCY THAT MIGHT ARISE.

His boss called him in for a last minute meeting on the morning he was supposed to be leaving.

\section{TARGETS}

Complement/New: His notes specified/said that the old man had sold Harold a camel.

Complement/Given: His notes specified/said that Harold bought the camel from an old man.

Noncomplement/New: The old man had sold Harold a camel, his boss's notes specified.

Noncomplement/Given: Harold bought the camel from an old man, his boss's notes specified.

He wondered why Harold wasn't travelling by jeep.

Pam had just moved into a new house and was about to begin cleaning out the attic.

Her son came into the house crying that he had been stung by some wasps or ants.

She calmed him down and told him it was wasps/ants that bit him. 
As she started back up to the attic, she thought about all of the work she had to do.

PAM KNEW THAT IT WOULD BE QUITE A WHILE BEFORE SHE WAS FINISHED.

AFTER MAKING SEVERAL TRIPS BRINGING THE JUNK DOWNSTAIRS, SHE DECIDED SHE WOULD TAKE A BREAK.

Her husband arrived home from work early in the evening.

TARGETS

Complement/New: He noticed/decided that it was wasps that bit their son.

Complement/Given: He noticed/decided that the wasps that bit their son were unusual.

Noncomplement/New: It was wasps that bit their son, he noticed.

Noncomplement/Given: The wasps that bit their son were unusual, he noticed.

The welts were red but the swelling wasn't bad.

Mark had grown up in the city but he had always wanted to live in the country.

Still, toward Easter, he decided to book the train or plane to the city to visit his parents.

He finally chose the train/plane.

Mark couldn't understand why people like his parents preferred to live in the city.

MARK REALLY ENJOYED LIVING IN THE COUNTRY.

HE LOVED ALL THE OPEN SPACES AND THE CLEAN FRESH AIR.

On Saturdays, Mark played golf with his neighbour, Fred.

\section{TARGETS}

Complement/New: Fred saw/guessed that Mark booked the train for his parents'.

Complement/Given: Fred saw/guessed that Mark was travelling on the train to visit his parents.

Noncomplement/New: Mark was travelling to his parents' on the train, Fred saw.

Noncomplement/Given: Mark was travelling on the train to visit his parents, Fred saw.

He knew that some modes of transportation made Mark nervous.

*As soon as breakfast was over, Sally's entire family got in the car.

They often helped others by fixing some church or barn.

Today, they spent the entire morning working with all their neighbours painting the church/barn.

After lunch, Sally spent the afternoon playing.

SHE ENJOYED JUMPING IN THE HAYSTACKS OUT IN THE FIELD.

FROM THERE, SHE WATCHED A SPARROW HAD BUILT A NEST IN THE BIG WILLOW TREE.
When Sally came in for dinner, she saw that her aunt was visiting.

\section{TARGETS}

Complement/New: She demonstrated/maintained that the building that Sally painted was a church.

Complement/Given: She demonstrated/maintained that Sally painted the church with some neighbours.

Noncomplement/New: The building that Sally painted was a church, her aunt demonstrated.

Noncomplement/Given: Sally painted the church with some neighbours, her aunt demonstrated.

Sally thought about what a full day it had been.

*It was Alex's first trip to the zoo and he was amazed at the wild animals.

Alex was always thrilled by the bears and lions.

After seeing the animals, he decided that his favourite animal was the bear/lion.

Alex's mother was glad that Alex seemed to be enjoying his trip to the zoo.

IT WAS SO LARGE THAT ALEX WAS STARTING TO GET TIRED FROM ALL THE WALKING.

THEY DECIDED TO STOP AT A HOTDOG STAND AND REST.

On Monday, Alex's teacher asked him to tell the class about his trip to the zoo.

\section{TARGETS}

Complement/New: She detected/imagined that his favorite animal was the bear.

Complement/Given: She detected/imagined that the bear was particularly large.

Noncomplement/New: His favorite animal was the bear, she detected.

Noncomplement/Given: The bear was particularly large, she detected.

The beasts were impressive but scared many children.

Bob always looked forward to Monday nights because that's when some of the guys from work came over to watch Monday night football on TV.

Usually, he got an oversupply of wine or beer in case anyone wanted a drink.

This week the refrigerator was stocked with wine/beer.

When their local team was on was the most fun.

THEY WOULD YELL, CHEER, AND MAKE A LOT OF NOISE.

EVERY WEEK, THEY'D PUT THEIR MONEY INTO A POOL AND BET ON THE FINAL SCORE.

This week, Bob's wife sat and watched the game with them.

\section{TARGETS}

Complement/New: She observed/imagined that the refrigerator was stocked with wine. 
Complement/Given: She observed/imagined that the wine supply was in the refrigerator.

Noncomplement/New: The refrigerator was stocked with wine, she observed.

Noncomplement/Given: The wine supply was in the refrigerator, she observed.

She poured herself some raspberry punch.

Gus liked to play sports that allowed him to spend time outdoors.

Most years, he devoted a lot of time to either tennis or golf.

Lately, tennis/golf was his favourite sport.

He knew summer was coming and he wanted to be sure he was in good condition.

HE JOINED A HEALTH SPA AND STARTED LIFTING WEIGHTS.

ALSO, HE AND HIS SON BEGAN JOGGING EVERY EVENING AFTER WORK.

As Gus pulled in to the gym's parking lot one day, he noticed a group of his friends were just going in the front door.

\section{TARGETS}

Complement/New: One friend remembered/mentioned that Gus's favourite sport was tennis.

Complement/Given: One friend remembered/mentioned that tennis was Gus's favourite sport.

Noncomplement/New: Gus's favourite sport was tennis, one friend remembered.

Noncomplement/Given: Tennis was Gus's favourite sport, one friend remembered.

He had taken a peek in Gus's luggage carrier.

*Joan had a very romantic boyfriend.

Last year for Valentine's Day he decided to give her a necklace with either diamonds or rubies.

In the end, he decided on the diamonds/rubies.

Joan loved to make all the girls at work jealous by bragging about her boyfriend.

THEY HAD BEEN DATING FOR A COUPLE OF YEARS AND EVERYONE ASSUMED IT WOULDN'T BE LONG BEFORE THEY WERE MARRIED.

WHEN SHE MET HIS PARENTS, THEY MADE HER FEEL AS THOUGH SHE WAS ONE OF THE FAMILY.

Her sister told her how lucky she was to have a boyfriend who bought her such nice gifts.

\section{TARGETS}

Complement/New: She learned/recollected that Joan's Valentine pendant had a diamond.

Complement/Given: She learned/recollected that Joan's diamond was set in a pendant.

Noncomplement/New: Joan's Valentine necklace had diamonds, she learned.
Noncomplement/Given: Joan's diamond was set in a pendant, she learned.

They daydreamed about the engagement ring Joan would surely get one day.

*Ever since her mother had taken her to see Santa Claus, Cathy had been counting the days until Christmas.

Cathy's mother suspected that Cathy badly wanted a bike or a doll.

Cathy finally asked Santa Claus for a bike/doll for Christmas.

When Cathy had gotten home that evening, she told her father about her trip to see Santa.

HER FATHER HADN'T BEEN ABLE TO KEEP FROM SMILING WHEN HE LOOKED AT THE PICTURE OF HER SITTING ON SANTA'S LAP.

CATHY WAS SO EXCITED THAT SHE HADN'T BEEN ABLE TO SLEEP.

Cathy's parents had invited her grandparents over to spend the holiday with them.

\section{TARGETS}

Complement/New: They determined/speculated that Cathy asked Santa Claus for the bike.

Complement/Given: They determined/speculated that Cathy asked for the bike from Santa Claus.

Noncomplement/New: Cathy asked Santa Claus for the bike, they determined.

Noncomplement/Given: It was Santa Claus that Cathy asked for the bike, they determined.

They hoped that the painting set would please their grandchild.

John had been a detective for only two months when he was called to his first murder scene.

Someone reported an attack with a knife or a gun.

He found a woman lying on the sidewalk with a knife/gun lying beside her.

On a tip from a witness, John cornered the suspect who quickly gave himself up.

TWO PATROL CARS HAD PULLED INTO THE ALLEY.

ONE CAR CAME FROM EACH DIRECTION, SO THE SUSPECT KNEW HE WAS BEATEN.

At the trial, John was ready for any question from the defense attorney.

\section{TARGETS}

Complement/New: The attorney perceived/emphasized that John found a knife beside the woman.

Complement/Given: The attorney perceived/ emphasized that the knife that John found was beside a woman.

Noncomplement/New: John found a knife beside the woman, the attorney perceived. 
Noncomplement/Given: The knife that John found was beside a woman, the attorney perceived.

He was pursuing the issue of fingerprints.

One day Bonny read about a vegetable diet in a magazine and she thought it might be worth trying.

She thought that Sidney had planted either corn or peas in the garden.

A quick glance revealed rows of her favourite, corn/peas.

She had been on so many diets in the past which had required great sacrifice.

SHE THOUGHT THIS ONE, HOWEVER, SOUNDED AS THOUGH IT WOULDN'T BE THAT BAD.

IF THIS DIDN'T SUCCEED IN HER LOSING WEIGHT THEN SHE DIDN'T KNOW WHAT ELSE SHE COULD TRY.

One day Bonny was telling her secretary about the diet.

TARGETS

Complement/New: She was reminded/believed that Bonny's favourite vegetable was corn.

Complement/Given: She was reminded/believed that the corn was the favourite vegetable of Bonny.

Noncomplement/New: Bonny's favourite vegetable was corn., she was reminded.

Noncomplement/Given: The corn was the favourite vegetable of Bonny, she was reminded.

Bonny reminded her about her award-winning garden of last year.

*Don and Susan decided to spend the evening watching a movie at the local cinema.

When they walked into the lobby, Susan was intent on getting either some chocolate or popcorn.

She arrived at her seat with an evening's worth of chocolate/popcorn.

The theatre was so crowded they had to sit in the second row.

SUSAN HATED SITTING SO CLOSE BECAUSE IT ALWAYS GAVE HER A HEADACHE.

THERE WAS ALSO A GROUP OF YOUNG KIDS THAT WERE MAKING NOISE AND THROWING THINGS.

After the movie while they were visiting with Susan's sister, they told her all about the movie.

\section{TARGETS}

Complement/New: She revealed/assumed that it was chocolate that Susan bought at the movie.

Complement/Given: She revealed/assumed that Susan bought the chocolate at the movie.

Noncomplement/New: It was chocolate that Susan bought at the movie, she revealed.
Noncomplement/Given: Susan bought the chocolate at the movie, she revealed.

A nice pot of herbal tea would hit the spot.

*Jane loved to spend the weekend at her grandparents' house.

She liked to see whether a hawk or an owl had claimed the large nest in the willow tree.

This time, she spotted an hawk/owl in the nest.

One day when it was especially warm, she decided to take a walk down by the lake and go for a swim.

WHEN JANE GOT TO THE LAKE, SOME FRIENDS WERE ALREADY THERE SWIMMING.

THEY HAD TIED A ROPE TO A BRANCH IN A TREE AND WERE USING IT TO SWING OUT INTO THE WATER.

Back at the house, Jane's brother had just arrived and was sitting at the dinner table.

TARGETS

Complement/New: He correctly guessed/bet that the bird by Jane's window was a/an hawk.

Complement/Given: He correctly guessed/bet that the hawk appeared by Jane's window.

Noncomplement/New: The bird by Jane's window was a hawk, he correctly guessed.

Noncomplement/Given: The hawk appeared by Jane's window, he correctly guessed.

This was surprising since he wasn't a nature lover.

Chris and Randy had decided to spend the afternoon investigating an old abandoned house in their neighbourhood.

As Randy started up the front stairs in front of Chris, a large roach or centipede ran out and startled him.

Chris identified it as a roach/centipede.

The front door creaked as they slowly pushed it open and stepped inside.

IT WAS VERY DARK BECAUSE MOST OF THE WINDOWS HAD BEEN BOARDED.

AS THEY MADE THEIR WAY THROUGH THE HOUSE, THEY HAD TO BRUSH AWAY COUNTLESS COBWEBS.

They were both so scared they turned and ran out of the house and all the way home.

\section{TARGETS}

Complement/New: Their mother established/presumed that Randy was startled by a roach.

Complement/Given: Their mother established/presumed that it was Randy that the roach had startled.

Noncomplement/New: Randy was startled by a roach, their mother established.

Noncomplement/Given: It was Randy that the roach had startled, their mother established. 
They were seen occasionally but didn't thrive in this climate.

Cindy couldn't stand her brother because she felt he was always trying to be a pest.

As soon as their parents left he would always tease her either with his frog or his snake.

Today, it seemed, was a frog/snake day.

Then he began to chase her around the house.

EVERY TIME HE CAUGHT UP TO HER HE'D PULL ON HER HAIR.

FINALLY, HE LEFT HER ALONE AND CINDY WENT OUT IN THE BACK YARD TO PLAY WITH HER DOLLS.

Later that afternoon, when their parents came home, they wanted to know what had happened while they were gone.

TARGETS

Complement/New: They grasped/supposed that Cindy's brother teased her with the frog.

Complement/Given: They grasped/supposed that it was Cindy's brother that teased her with the frog.

Noncomplement/New: Cindy's brother teased her with the frog, they grasped.

Noncomplement/Given: It was Cindy's brother that teased her with the frog, they grasped.

There were slimy trails along the hallway tile.

*Nancy wanted to do something nice for her mother so she decided to make a salad for dinner.

She thought she had to borrow either some onions or lettuce from the neighbour.

Ultimately, she had to borrow some onions/lettuce.

Nancy could hear her mother upstairs taking a shower.

NANCY WISHED SHE WAS A LITTLE OLDER SO

THAT SHE COULD USE THE

STOVE.

THEN SHE COULD HAVE COOKED THE ENTIRE DINNER.

When she came downstairs, Nancy's mother noticed something different in the refrigerator.

\section{TARGETS}

Complement/New: She recognized/guessed that Nancy asked her neighbour to lend her onions.

Complement/Given: She recognized/guessed that Nancy had borrowed the onions from her neighbour.

Noncomplement/New: Nancy asked her neighbour to lend her onions, her mother recognized.

Noncomplement/Given: Nancy had borrowed the onions from her neighbour, her mother recognized.

They discussed the day's events over the fresh salad.

*When Lisa was preparing for the party she gave Saturday, she had wanted to be sure she had everything she needed.
Lisa knew many of her friends were fond of the punch that she would spike with either whiskey or vodka.

The small corner liquor store had only whiskey/vodka available.

After she left the liquor store she decided to stop at the bakery and buy a cake.

AT FIRST, SHE COULDN'T DECIDE WHICH KIND TO BUY.

SHE KNEW MOST PEOPLE LIKE CHOCOLATE SO SHE BOUGHT A CHOCOLATE CAKE WITH VANILLA FROSTING.

Later in the evening, Lisa was talking to her city councillor.

TARGETS

Complement/New: The politician confirmed/suspected that Lisa bought whiskey for the spiked punch.

Complement/Given: The politician confirmed/suspected that the whiskey was used by Lisa for the spiked punch.

Noncomplement/New: Lisa bought the whiskey for the spiked punch, the politician confirmed.

Noncomplement/Given: The whiskey was used by Lisa for the spiked punch, the politician confirmed.

The country was in a strange trade dispute with the Russians.

Jill had a lot of fun outdoors during the winter.

Jill though that there would be either snow or sleet for the weekend.

The walkman radio verified that snow/sleet was going to fall.

She enjoyed being able to get the exercise and have fun at the same time.

IN THE MIDDLE OF WINTER, IT IS SO COLD THAT JILL WOULD OFTEN WEAR THREE LAYERS OF CLOTHING.

WHENEVER SHE WOULD COME INSIDE, HOWEVER, HER MOTHER WOULD HAVE A CUP OF HOT CHOCOLATE WAITING FOR HER.

Jill got home at 5:00 P. M.

TARGETS

Complement/New: Her mother told/mentioned that the weather forecast predicted snow.

Complement/Given: Her mother told about/mentioned the snow that the weather forecast predicted.

Noncomplement/New: The weather forecast predicted snow, her mother disclosed.

Noncomplement/Given: The snow predicted in the weather forecast was disclosed by her mother.

Jill's mother hadn't heard the forecast since yesterday evening.

Jean was in such a good mood that she decided to walk home from work. 
Her walk took her by an odd flower shop that always had either daisies or roses in the front window.

This time, there were daisies/roses on display.

AS SHE CONTINUED HER WALK SHE FELT A BREEZE START TO BLOW.

THE COOL, FRESH AIR FELT SO INVIGORATING THAT SHE WISHED EVERY DAY COULD BE LIKE THIS ONE.

When Jean turned the corner to her street, she noticed a car parked in front of her house.

Jean was happy to see her girlfriend waiting on her front porch because they hadn't seen each other in a couple of months.

\section{TARGETS}

Complement/New: Her girlfriend proved/assumed the flower shop was displaying daisies.

Complement/Given: Her girlfriend proved/assumed the daisies were displayed by the flower shop.

Noncomplement/New: The flower shop was displaying daisies, her girlfriend proved.

Noncomplement/Given: The daisies were displayed by the flower shop, her girlfriend proved.

She knew which route Jean followed home from the office.

*Pete rode in the boat for about a half hour before they arrived at the captain's favourite fishing spot.

In no time, Pete could make out a huge shark or a bass at the end of his line.

He pulled in a beautiful shark/bass.

After that, two or three hours passed without anyone catching a thing.

THE CAPTAIN MOVED THE BOAT TO A DIFFERENT SPOT AND PETE CAUGHT A COUPLE OF SMALL FISH BUT NOTHING WORTH KEEPING.

THE CAPTAIN TRIED TO HELP BY THROWING SOME BAIT INTO THE WATER.

When Pete got home, his wife wanted to hear all about his fishing trip.

\section{TARGETS}

Complement/New: She overlooked/bet that Pete's first fish was a shark.

Complement/Given: She overlooked/bet that the shark was Pete's first fish.

Noncomplement/New: Pete's first fish was a shark, she overlooked.

Noncomplement/Given: The shark was Pete's first fish, she overlooked.

If not for her annual report, she would have been out there with him.

\section{Appendix B Questionnaire of Experiment 2}

We would value your insights about your own performance in the experiment. Please answer the questions in order, and do not go back from one question to an earlier question.

1. Please describe briefly what you thought was the main point of this experiment.

2. Did you find it easy or hard to answer the comprehension questions after each passage?

EASY HARD (circle one)

3. Did you notice anything special about the passages themselves?

\section{YES NO}

a) If $\mathrm{NO}$, proceed to question 4 .

b) If YES, what did you notice about them?

(4) Did you notice any repeating pattern in the passages? YES NO

a) If NO, proceed to question 5 .

b) If YES, please describe the pattern.

(5) Either because of repeating patterns in the passages or for any other reason, did you use a special strategy when you read the passages?

\section{YES NO}

a) If NO, jump to End.

b) If YES, please describe your strategy.

Thank you once again for your help. It is most appreciated.

\section{References}

Albrecht, J. E., \& Myers, J. L. (1995). Role of context in accessing distant information during reading. Journal of Experimental Psychology Learning Memory and Cognition, 21, 1459-1468. doi:10.1037 /0278-7393.21.6.1459

Albrecht, J. E., \& O'Brien, E. J. (1993). Updating a mental model: Maintaining both local and global coherence. Journal of Experimental Psychology Learning Memory and Cognition, 19, 1061-1070. doi:10.1037/0278-7393.19.5.1061

Barton, S. B., \& Sanford, A. J. (1993). A case study of anomaly detection: Shallow semantic processing and cohesion establishment. Memory \& Cognition, 21, 477-487.

Bredart, S., \& Modolo, K. (1988). Moses strikes again: Focalization effect on a semantic illusion. Acta Psychologica, 67, 135-144.

Carpenter, P. A., \& Just, M. A. (1975). Sentence comprehension: A psycholinguistic processing model of verification. Psychological Review, 82, 45-73. 
Christianson, K., Williams, C. C., Zacks, R. T., \& Ferreira, F. (2006). Younger and older adults" "good-enough" interpretations of garden-path sentences. Discourse Processes, 42, 205-238. doi:10.1207/s15326950dp4202_6

Clark, H. H., \& Chase, W. G. (1972). On the process of comparing sentences against pictures. Cognitive Psychology, 3, 472-517.

Clark, H. H., \& Haviland, S. E. (1977). Comprehension and the givennew contract. In R. O. Freedle (Ed.), Discourse production and comprehension (pp. 1-40). Norwood: Ablex.

Cohen, G. (1979). Language comprehension in old age. Cognitive Psychology, 11, 412-429.

Conrad, F. G., \& Rips, L. J. (1986). Conceptual combination and the given/ new distinction. Journal of Memory and Language, 25, 255-278.

Cook, A. E., \& O’Brien, E. J. (2014). Knowledge activation, integration, and validation during narrative text comprehension. Discourse Processes, 51, 26-49.

Erickson, T. D., \& Mattson, M. E. (1981). From words to meaning: A semantic illusion. Journal of Verbal Learning and Verbal Behavior, 20, 540-551. doi:10.1016/S0022-5371(81)90165-1

Ferreira, F., Bailey, K. G. D., \& Ferraro, V. (2002). Good-enough representations in language comprehension. Current Directions in Psychological Science, 11, 11-15. doi:10.1111/1467-8721.00158

Ferretti, T. R., Singer, M., \& Harwood, J. (2013). Processes of discourse integration: Evidence from event-related brain potentials. Discourse Processes, 50, 165-186. doi:10.1080/0163853X.2013.766123

Ferretti, T., Singer, M., \& Patterson, C. (2008). Electrophysiological evidence for the time-course of verifying text ideas. Cognition, 108, 881-888.

Fletcher, C. R. (1981). Short-term memory processes in text comprehension. Journal of Verbal Learning and Verbal Behavior, 20, 564-574.

Gerrig, R. J., \& Prentice, D. A. (1991). The representation of fictional information. Psychological Science, 2, 336-340. doi:10.1111 /j.1467-9280.1991.tb00162.x

Gernsbacher, M. A. (1990). Language comprehension as structure building. Hillsdale: Erlbaum.

Glenberg, A. M., Sanocki, T., Epstein, W., \& Morris, C. (1987). Enhancing calibration of comprehension. Journal of Experimental Psychology: General, 116, 119-136. doi:10.1037/00963445.116.2.119

Halliday, M. A. K. (1967). Notes on transitivity and theme in English: Part 2. Journal of Linguistics, 3, 199-244.

Harris, R. J. (1973). Answering questions containing marked and unmarked adjectives and adverbs. Journal of Experimental Psychology, 97.

Haviland, S. E., \& Clark, H. H. (1974). What's new? acquiring new information as a process in comprehension. Journal of Verbal Learning and Verbal Behavior, 13, 512-521.

Hockett, C. F. (1958). A course in modern linguistics. New York: Macmillan.

Hornby, P. A. (1972). The psychological subject and predicate. Cognitive Psychology, 3, 632-642.

Hornby, P. A. (1974). Surface structure and presupposition. Journal of Verbal Learning and Verbal Behavior, 13, 530-538.

Isberner, M.-B., \& Richter, T. (2013). Can readers ignore implausibility? evidence for nonstrategic monitoring of event-based plausibility in language comprehension. Acta Psychologica, 142, 15-22.

Kendeou, P., Smith, E. R., \& O'Brien, E. J. (2013). Updating during reading comprehension: Why causality matters. Journal of Experimental Psychology Learning Memory and Cognition, $39,854-865$.

Kintsch, W. (1980). Learning from text, levels of comprehension, or: Why would anyone read a story anyway. Poetics, 9, 7-98.
Kintsch, W. (1988). The role of knowledge in discourse comprehension: A construction-integration model. Psychological Review, 95, 163 182. doi:10.1037/0033-295X.95.2.163

Kintsch, W. (1998). Comprehension. New York: Cambridge University Press.

Kintsch, W., \& van Dijk, T. A. (1978). Toward a model of text comprehension and production. Psychological Review, 85, 363-394.

Klin, C. M. (1995). Causal inferences in reading: From immediate activation to long term memory. Journal of Experimental Psychology Learning Memory and Cognition, 21, 1483-1494.

Knoeferle, P., Urbach, T. P., \& Kutas, M. (2011). Comprehending how visual context influences incremental sentence processing: Insights from ERPs and picture-sentence verification. Psychophysiology, 48, 495-506.

Loftus, E. F. (1975). Leading questions and the eyewitness report. Cognitive Psychology, 7, 560-572.

Loftus, E. F., \& Zanni, G. (1975). Eyewitness testimony: The influence of the wording of a question. Bulletin of the Psychonomic Society, 5, $86-88$.

Long, D. L., \& Chong, J. L. (2001). Comprehension skill and global coherence: A paradoxical picture of poor comprehenders' abilities. Journal of Experimental Psychology Learning Memory and Cognition, 27, 1424-1429.

Lyons, J. (1977). Semantics. Cambridge: Cambridge University Press.

McKoon, G., \& Ratcliff, R. (1992). Inference during reading. Psychological Review, 99, 440-466. doi:10.1037/0033-295 X.99.3.440

McKoon, G., \& Ratcliff, R. (1998). Memory-based language processing: Psycholinguistic research in the 1990s. Annual Review of Psychology, 49, 25-42.

Noordman, G. M., Vonk, W., \& Kempff, H. J. (1992). Causal inferences during the reading of expository texts. Journal of Memory and Language, 31, 573-590.

O'Brien, E. J., \& Albrecht, J. E. (1992). Comprehension strategies in the development of a mental model. Journal of Experimental Psychology Learning Memory and Cognition, 18, 777-784. doi:10.1037/0278-7393.18.4.777

O’Brien, E. J., Cook, A. E., \& Guéraud, S. (2010). Accessibility of outdated information. Journal of Experimental Psychology Learning Memory and Cognition, 36, 979-991. doi:10.1037/a0019763

O’Brien, E. J., Lorch, R. F., \& Myers, J. L. (1998). Memory-based text processing [Special issue]. Discourse Processes, 26(2-3).

O'Brien, E. J., Plewes, P. S., \& Albrecht, J. E. (1990). Antecedent retrieval processes. Journal of Experimental Psychology Learning Memory and Cognition, 16, 241-249. doi:10.1037 /0278-7393.16.2.241

O’Brien, E. J., Shank, D. M., Myers, J. L., \& Rayner, K. (1988). Elaborative inferences during reading: Do they occur on-line? Journal of Experimental Psychology Learning Memory and Cognition, 14, 410-420. doi:10.1037/0278-7393.14.3.410

Otero, J., \& Kintsch, W. (1992). Failures to detect contradictions in a text: What readers believe versus what they read. Psychological Science, 3, 229-235. doi:10.1111/j.14679280.1992.tb00034.x

Rapp, D. N., \& Kendeou, P. (2009). Noticing and revising discrepancies as texts unfold. Discourse Processes, 46, 1-24. doi:10.1080/01638530802629141

Reder, L. H., \& Kusbit, G. W. (1991). Locus of the Moses Illusion: Imperfect encoding, retrieval, or match. Journal of Memory and Language, 30, 385-407.

Richter, T., \& Singer, M. (in press). Updating situational representations in reading. In M. Schober, A. Britt, \& D. Rapp (Eds.), Handbook of 
discourse processes (2nd ed.). Amsterdam, The Netherlands: Taylor $\&$ Francis.

Rinck, M., Hähnel, A., \& Becker, B. (2001). Using temporal information to construct, update, and retrieve situation models of narratives. Journal of Experimental Psychology Learning Memory and Cognition, 27, 67-80.

Sanford, A. J., \& Garrod, S. C. (2005). Memory-based approaches and beyond. Discourse Processes, 39, 205-224. doi:10.1080/0163853 X.2005.9651680

Sanford, A. J., \& Graesser, A. C. (2006). Shallow processing and underspecification. Discourse Processes, 42, 99-108. doi:10.1207 /s15326950dp4202_1

Schroeder, S., Richter, T., \& Hoever, I. (2008). Getting a picture that is both accurate and stable: Situation models and epistemic validation. Journal of Memory and Language, 59, 237-259.

Singer, M. (1976). Thematic structure and the integration of linguistic information. Journal of Verbal Learning and Verbal Behavior, 15, $549-558$.

Singer, M. (2006). Verification of text ideas during reading. Journal of Memory and Language, 54, 574-591.

Singer, M. (2009). Tacit verification of determinate and indeterminate text ideas. Canadian Journal of Experimental Psychology, 63, 185-192.

Singer, M. (2013). Validation in reading comprehension. Current Directions in Psychological Science, 22, 361-366.

Singer, M., \& Doering, J. C. (2014). Exploring individual differences in language validation. Discourse Processes, 51, 167-188.

Singer, M., \& Halldorson, M. (1996). Constructing and validating motive bridging inferences. Cognitive Psychology, 30, 1-38.

Singer, M., Halldorson, M., Lear, J. C., \& Andrusiak, P. (1992). Validation of causal bridging inferences. Journal of Memory and Language, 31, 507-524.

Singer, M., Harkness, D., \& Stewart, S. T. (1997). Constructing inferences in expository text comprehension. Discourse Processes, 24, $199-228$.
Staub, A., Rayner, K., Pollatsek, A., Hyönä, J., \& Majewski, H. (2007). The time course of plausibility effects on eye movements in reading: Evidence from noun-noun compounds. Journal of Experimental Psychology Learning Memory and Cognition, 33, 1162-1169. doi:10.1037/0278-7393.33.6.1162

Swets, B., Desmet, T., Hambrick, D. Z., \& Ferreira, F. (2007). The role of working memory in syntactic ambiguity resolution: A psychometric approach. Journal of Experimental Psychology: General, 136, 64-81.

van Berkum, J. J. A., Hagoort, P., \& Brown, C. M. (1999). Semantic integration in sentences and discourse: Evidence from the N400. Journal of Cognitive Neuroscience, 11, 657-671. doi:10.1162 /089892999563724

van Berkum, J. J. A., Zwisterlood, P., Hagoort, P., \& Brown, C. M. (2003). When and how do listeners relate a sentence to the wider discourse? Evidence from the N400 effect. Cognitive Brain Research, 17, 701-718.

Wason, P. C. (1965). The contexts of plausible denial. Journal of Verbal Learning and Verbal Behavior, 4, 7-11. doi:10.1016/S0022-5371 (65)80060-3

Wilkes, A. L., \& Leatherbarrow, M. (1988). Editing episodic memory following the identification of error. Quarterly Journal of Experimental Psychology, 40A, 361-387. doi:10.1080 /02724988843000168

Winkielman, P., Huber, D. E., Kavanagh, L., \& Schwarz, N. (2012). Fluency of consistency: When thoughts fit nicely and flow smoothly. In B. Gawronski \& F. Strack (Eds.), Cognitive consistency: A fundamental principle in social cognition (pp. 89-111). New York: Guilford Press.

Yekovich, F. R., Walker, C. H., \& Blackman, H. S. (1979). The role of presupposed and focal information in integrating sentences. Journal of Verbal Learning and Verbal Behavior, 18, 535-548. 